\title{
Demonstration of a Coupled Metabolism-Efflux Process at the Choroid Plexus as a Mechanism of Brain Protection Toward Xenobiotics
}

\author{
Nathalie Strazielle and Jean-François Ghersi-Egea \\ Institut National de la Santé et de la Recherche Médicale U433, Faculté de Médecine Laennec, Lyon 69008, France, and \\ Institut National de la Santé et de la Recherche Médicale U 325, Institut Pasteur de Lille, Lille 59000, France
}

\begin{abstract}
Brain homeostasis depends on the composition of both brain interstitial fluid and CSF. Whereas the former is largely controlled by the blood-brain barrier, the latter is regulated by a highly specialized blood-CSF interface, the choroid plexus epithelium, which acts either by controlling the influx of bloodborne compounds, or by clearing deleterious molecules and metabolites from CSF. To investigate mechanisms of brain protection at the choroid plexus, the blood-CSF barrier was reconstituted in vitro by culturing epithelial cells isolated from newborn rat choroid plexuses of either the fourth or the lateral ventricle. The cells grown in primary culture on semipermeable membranes established a pure polarized monolayer displaying structural and functional barrier features, (tight junctions, high electric resistance, low permeability to paracellular markers) and maintaining tissue-specific markers (transthyretin) and specific transporters for micronutriments (amino acids, nucleosides). In particular, the high enzymatic drug metabolism capacity of choroid plexus was preserved in the in vitro blood-
\end{abstract}

The CSF circulatory system has for long been considered as a drainage system for the degradation products of cerebral metabolism, as well as a mechanical means of achieving buoyancy and intracranial volume adjustment. New evidence suggests more specific CSF functions, including buffering of brain extracellular fluid ions and other solutes, hormone delivery, paracrine neurotransmission, and mediation of immune responses (Johanson, 1995; Davson and Segal, 1996; Boulton et al., 1997). CSF is secreted for a large part by the three types of choroid plexuses located in the ventricular cisternae. Similarly to other secreting/ transporting epithelia, the choroidal epithelium, which overlies a highly vascularized stromal core, is composed of a tight monolayer of polarized cells and forms the actual barrier between blood and CSF. Choroid plexuses have been shown to participate

\footnotetext{
Received Feb. 26, 1999; revised May 7, 1999; accepted May 13, 1999.

This work was supported by Sidaction, the Agence Nationale de Recherche sur le Sida, and the Institut National de la Santé et de la Recherche Médicale (PRISME 98-01). N.S. is a recipient of the Agence Nationale de Recherche sur le Sida. We also thank the Région Nord-Pas de Calais for financial support. We thank Profs. Joe Fenstermacher and Clifford Patlak, and Dr. Marie-Francoise Belin for advice and critical discussion. We thank Prof. Romeo Cecchelli for free access to his technical facilities, Prof. Joe Fenstermacher for access to his electron microscopy Center, and Dr. Simon Saule for access to his molecular biology equipment. We also thank Wendy Finnegan for processing the transmission electron micrographs and JeanMarc Merchez for help with preparation of the photographs.

Correspondence should be addressed to Dr. Jean-François Ghersi-Egea, Institut National de la Santé et de la Recherche Médicale U 433, Faculté de Médecine R.T.H. Laennec, Rue Guillaume Paradin, F 69372 Lyon Cedex, 08 France.

Copyright (C) 1999 Society for Neuroscience $0270-6474 / 99 / 196275-15 \$ 05.00 / 0$
}

CSF interface. Using this model, we demonstrated that choroid plexuses can act as an absolute blood-CSF barrier toward 1-naphthol, a cytotoxic, lipophilic model compound, by a coupled metabolism-efflux mechanism. This compound was metabolized in situ via uridine diphosphate glururonosyltransferase-catalyzed conjugation, and the cellular efflux of the glucurono-conjugate was mediated by a transporter predominantly located at the basolateral, i.e., bloodfacing membrane. The transport process was temperaturedependent, probenecid-sensitive, and recognized other glucuronides. Efflux of 1-naphthol metabolite was inhibited by intracellular glutathione $S$-conjugates. This metabolism-polarized efflux process adds a new facet to the understanding of the protective functions of choroid plexuses.

Key words: choroid plexus epithelial cell culture; blood-brain barrier; brain protection; drug metabolism; multidrug resistanceassociated protein; UDP-glucuronosyl transferase; glutathione S-transferase

in the various functions attributed to CSF, and accordingly, epithelial cells are shown to be highly specialized cells. They possess polarized specific transport systems that allow blood to brain influx of micronutriments or brain to blood efflux of harmful neurotransmitter metabolites and various neuroactive drugs (Spector, 1986; Davson and Segal, 1996; Suzuki et al., 1997). The choroidal epithelium is a source of and a target for hormones and other neuroactive compounds (Bondy et al., 1992; Nilsson et al., 1992; Tu et al., 1992; Yamamoto et al., 1996; Chodobski et al., 1997). Moreover, in view of the considerable local activity of catechol- $O$-methyl transferase and monoamine oxidase $\mathrm{B}$, choroid plexuses probably represent an inactivation site and biochemical barrier for neurotransmitters (Lindvall et al., 1980). Finally, a high capacity for phase I (functionalization) and phase II (conjugation) drug metabolism has been recently described in the choroidal tissue (Johnson et al., 1993; Ghersi-Egea et al., 1994; Leininger-Muller et al., 1994; Strazielle and Ghersi-Egea, 1999). These two last features, coincident with the presence of efflux systems, hint at an additional function of choroid plexuses as a major detoxification and protective organ within the brain.

To probe into this new mechanism of brain protection, we tested whether the choroid plexus epithelium could act as an efficient enzymatic barrier impeding the blood-to-CSF transfer of 1-naphthol, a model molecule for lipid soluble xenobiotics, which is potentially cytotoxic and genotoxic (Wilson et al., 1996), and is also substrate for a uridine $5^{\prime}$-diphosphate (UDP)glucuronosyltransferase (UGT), one of the conjugation enzymes 
largely expressed in the choroid plexus. Conjugated metabolites may in some cases be toxic, and their clearance from the cells, referred to as phase III, is a crucial step in xenobiotic metabolism (Ishikawa, 1992). We investigated as a second goal, the fate of the resulting 1-naphthyl- $\beta$-D-glucuronide $(\mathrm{NG})$, and its site of export from the polarized choroidal epithelial cell. To elucidate simultaneously kinetics of transepithelial flux, metabolic processes and polarized export mechanisms, we have developed an in vitro model of the choroidal epithelium. This system, which reproduces the characteristic features of the in vivo blood-CSF barrier, consists of a polarized monolayer grown on a semipermeable membrane and allows separate access to apical, basolateral, and intracellular domains.

Some of these results have been published in abstract form (Strazielle and Ghersi-Egea, 1997a, 1998).

\section{MATERIALS AND METHODS}

\section{Primary cell culture of choroidal epithelial cells}

Animal care and procedures have been conducted according to the guidelines approved by the French Ethical Committee (decree 87-848), the European Community directive 86-609-EEC, and meet the Neuroscience Society guidelines. Timed pregnant rats were obtained from IFFA Credo (St. Germain sur l'Arbresle, France). Primary cultures of epithelial cells from 1- or 2-d-old rat choroid plexuses were prepared using a modification of the method described by Tsutsumi et al. (1989). Rat pups were killed, the brain was exposed, and choroid plexuses from fourth ventricle $(4 \mathrm{~V})$ and lateral ventricles $(\mathrm{LVs})$ were rapidly dissected under stereomicroscope and separately kept in a warm $\left(37^{\circ} \mathrm{C}\right)$ culture medium consisting of Ham's F-12 and DMEM (1:1) supplemented with $10 \%(\mathrm{v} / \mathrm{v})$ fetal calf serum, $2 \mathrm{~mm}$ glutamine, and $50 \mu \mathrm{g} / \mathrm{ml}$ gentamycine (all reagents from Life Technologies, Gaithersburg, MD).

The tissue was rinsed twice in PBS (without $\mathrm{Ca}^{2+}$ and $\mathrm{Mg}^{2+}$ ) and then incubated in PBS containing $1 \mathrm{mg} / \mathrm{ml}$ pronase (Sigma, St Louis, $\mathrm{MO}$ ) for $25 \mathrm{~min}$ at $37^{\circ} \mathrm{C}$. Predigested plexuses were recovered by sedimentation and washed once with PBS. The supernatant containing mostly single nonepithelial cells was discarded, and the large clumps of epithelial cells were briefly shaken in $0.025 \%$ trypsin (Life Technologies) containing $12.5 \mu \mathrm{g} / \mathrm{ml}$ DNase I (Boehringer Mannheim, Mannheim, Germany). The supernatant resulting from sedimentation was withdrawn and kept on ice, with $10 \%$ fetal calf serum. Fresh trypsin solution was added to the tissue, and this step was repeated five times. Cells were pelleted by centrifugation at $800 \times g$ for $5 \mathrm{~min}$, and pellets were resuspended in culture media. Epithelial cells were further enriched by differential attachment on plastic dishes. After $2 \mathrm{hr}$ of incubation at $37^{\circ} \mathrm{C}$ resulting in fibroblast, endothelial cell and macrophage adhesion to the plastic, supernatants were collected and cells were seeded on TranswellClear filter inserts $\left(12 \mathrm{~mm}\right.$ diameter, $1 \mathrm{~cm}^{2}$ surface, $0.4 \mu \mathrm{m}$ pore size; Costar Plastics, Cambridge, MA) precoated on the upper side with basal lamina components at a density of $1.3 \mathrm{~cm}^{2} /$ plexus from the fourth ventricle and $0.65 \mathrm{~cm}^{2} /$ plexus from the lateral ventricle. The medium was changed after $48 \mathrm{hr}$, then every other day. Coating with laminin (Becton Dickinson, Bedford, MA) was as described by the manufacturer, and coating with collagen was performed according to Dehouck et al. (1990).

Culture media was supplemented with $5 \mu \mathrm{g} / \mathrm{ml}$ insulin, $5 \mu \mathrm{g} / \mathrm{ml}$ transferrin, $5 \mathrm{ng} / \mathrm{ml}$ sodium selenite, $10 \mathrm{ng} / \mathrm{ml}$ epidermal growth factor, 2 $\mu \mathrm{g} / \mathrm{ml}$ hydrocortisone, $5 \mathrm{ng} / \mathrm{ml}$ basic fibroblast growth factor, and $500 \mu \mathrm{M}$ hypoxanthine. Laminin-coated inserts (without cells) were kept in the same conditions. Unless otherwise stated, experiments were performed within 5-7 d after confluence.

\section{Transepithelial electric resistance}

The transepithelial electric resistance (TEER) was measured in tissue culture medium with a Millicell-ERS resistance meter (Millipore, Bedford, MA). Independent measurements were recorded on three cell culture areas for each filter and were averaged. TEER of laminin-coated, cell-free filters was measured as background and was subtracted from values of the cell-seeded filters. TEER was expressed as ohms times square centimeter. Because TEER is temperature-dependent (Misfeldt et al., 1976), care was taken to record the resistance at a constant temperature of $30^{\circ} \mathrm{C}$.

\section{Immunocytochemistry}

Cells were fixed for $20 \mathrm{~min}$ at $4^{\circ} \mathrm{C}$ in $4 \%$ paraformaldehyde in PHEM buffer (in mM: 60 PIPES, 25 HEPES, 10 EGTA, $2 \mathrm{MgCl}_{2}$, and $140 \mathrm{NaCl}$, $\mathrm{pH}$ 6.9). For F-actin labeling, cells were permeabilized with cold acetone $\left(-20^{\circ} \mathrm{C}\right)$ for $1 \mathrm{~min}$, followed by a $30 \mathrm{~min}$ incubation at room temperature in BODIPY FL-phallacidin (165 nM; Molecular Probes Europe BV, Leiden, The Netherlands). For labeling of cytokeratins and occludin, free aldehydes were quenched with $75 \mathrm{mM} \mathrm{NH}_{4} \mathrm{Cl}$ and $20 \mathrm{~mm}$ glycine in PBS for $10 \mathrm{~min}$. Cells were washed in PBS and permeabilized with methanol at $-20^{\circ} \mathrm{C}$ for 3 min, followed by a blocking step in $10 \%$ fetal calf serum in PBS for $30 \mathrm{~min}$. All incubations and washes of antibodies were performed using the same buffer. Cells were incubated overnight at $4^{\circ} \mathrm{C}$ with either one of the following primary antibodies, anti-cytokeratin mouse monoclonal Pan (Sigma) used at 1:100 or anti-occludin rabbit polyclonal (Zymed, San Francisco, CA) used at 1:200. Controls were run with isotype IgGs (mouse from Serotec, Oxford, England and rabbit from Zymed). After four washes, FITC-conjugated anti-mouse $\operatorname{IgG}$ (1:50; Jackson ImmunoResearch, West Grove, PA) and BODIPY FLconjugated anti-rabbit IgG (1:100; Molecular Probes) secondary antibodies were used for $1 \mathrm{hr}$ at room temperature. After washing and mounting, the preparations were examined on a Leitz DMRB fluorescence microscope using a $40 \times$ oil immersion lens.

\section{Transmission electron microscopy}

Samples for electron microscopy were prepared on cells cultured for $8 \mathrm{~d}$. Tissue or cells were fixed in $2 \%$ glutaraldehyde in $0.12 \mathrm{M}$ sodium cacodylate buffer and $1 \mathrm{mM} \mathrm{CaCl}_{2}, \mathrm{pH} 7.4$, for $30 \mathrm{~min}$ at $37^{\circ} \mathrm{C}$. All subsequent steps were performed at $4^{\circ} \mathrm{C}$. After washing, the samples were post-fixed with $1 \%$ osmium tetroxide $-1.5 \%$ potassium ferricyanide for $30 \mathrm{~min}$, washed again and stained in $1.2 \%$ uranyl acetate for $20 \mathrm{~min}$. Tissues were dehydrated in graded alcohol and resin-embedded.

Sections (1- to $2-\mu \mathrm{m}$-thick) were placed on a glass slide and stained with $1 \%$ toluidine blue for light microscopy observation. Adjacent silverto-pale gold ultrathin sections $(\sim 80-90 \mathrm{~nm})$ were cut with a diamond knife and picked up on formvar-coated, single-slot nickel grids. Grids were then stained with uranyl acetate and lead citrate and examined on a JEOL 1200EX electron microscope.

\section{$R N A$ isolation and RT-PCR}

Total cellular RNA was isolated from liver, choroid plexuses of newborn rat and from choroid plexus epithelial (CPE) cells at different stages of culture, according to Chomczynsky and Sacchi (1987) and used as a template for reverse transcription using oligo-dT as a primer. A $406 \mathrm{nt}$ fragment was then amplified using a primer containing nucleotides 75-94 and an antisense primer corresponding to nucleotides $463-480$ of the published transthyretin rat cDNA (Dickson et al., 1985). PCR products were cloned into pCR 2.1 using the TA Cloning kit (Invitrogen, Leek, The Netherlands), and the sequences were confirmed by dideoxy sequencing.

\section{Enzymatic measurements}

Choroidal tissue and choroidal cells scraped from culture inserts were homogenized in a $0.32 \mathrm{~m}$ sucrose, $50 \mathrm{~mm} \mathrm{~K}$ phosphate, $1 \mathrm{~mm}$ K EDTA, $0.1 \mathrm{~mm}$ dithiothreitol buffer, $\mathrm{pH} 7.4$, using a glass-glass homogenizer. Liver and cortical tissue cleared from meninges and superficial blood vessels were also sampled from newborn rats and treated similarly for comparative purposes. The resulting homogenates were used for enzyme measurements. NADPH-cytochrome P-450 reductase activity was measured at $25^{\circ} \mathrm{C}$ using cytochrome $c$ as a substrate, according to the method of Strobel and Dignam (1978) modified as previously described (GhersiEgea et al., 1989). The enzymatic activity of membrane-bound epoxide hydrolase was assayed at $37^{\circ} \mathrm{C}$ by measuring the rate of hydrolysis of benzo[a]pyrene-4,5-oxide in a spectrofluorimeter, according to the method of Dansette et al. (1970). The native activities of UGTs were measured toward 1-naphthol (Ghersi-Egea et al., 1987). The substrate $(0.5 \mathrm{~mm})$ was incubated with protein $(150-500 \mu \mathrm{g})$ and UDP-glucuronic acid (4 mM) in a $30 \mathrm{~mm}$ Tris- $\mathrm{HCl}, 0.6 \mathrm{~mm} \mathrm{MgCl}_{2}$ buffer at $\mathrm{pH}$ 7.4. The reaction was stopped by addition of ice-cold acetonitrile, and after centrifugation, the reaction mixture was analyzed by HPLC (see HPLC analysis section). Control measurements were performed by omitting either 1-naphthol or UDP-glucuronic acid in the reaction mixture. Glutathione $S$-transferase activity was determined according to Habig et al. (1974). Assays were conducted in $0.1 \mathrm{M}$ potassium phosphate, $\mathrm{pH} 6.5$ at $25^{\circ} \mathrm{C}$, using $1 \mathrm{~mm}$ glutathione and $1 \mathrm{~mm}$ 1-chloro-2,4-dinitrobenzene 
$(\mathrm{CDNB})$ as substrate. The complete assay mixture without protein homogenate was used as a control. The activity was strictly dependent on glutathione addition and totally inhibited after addition of $0.5 \mathrm{~mm}$ ethacrynic acid.

Total protein content was measured by the method of Petersen (1977), with bovine serum albumin as the standard.

\section{Permeability studies}

Culture inserts were rinsed once on both sides before initiating the permeability study. All incubations were performed on a rotating platform $(250 \mathrm{rpm})$ at $37^{\circ} \mathrm{C}$, and volumes added to both compartments of the insert were chosen as to be in equilibrium and to avoid any hydrostatic pressure. Some experiments were performed at $4^{\circ} \mathrm{C}$. Blood-to-CSF flux will be referred to as basolateral to apical transfer, whereas CSF-to-blood flux will be referred to as apical to basolateral transfer. In both cases, the flux is from the donor to the acceptor chamber. Unless otherwise stated, sets of four filters were studied for each experimental condition. Permeability studies were performed using $\left[{ }^{14} \mathrm{C}\right]$ sucrose $(350 \mathrm{mCi} / \mathrm{mmol}$; Amersham, Little Chalfont, England), $\left[{ }^{3} \mathrm{H}\right]$ thymidine $(74 \mathrm{Ci} / \mathrm{mmol}$; Moravek, Brea, CA), $\left[{ }^{3} \mathrm{H}\right]$ phenylalanine (50 Ci/mmol; Moravek), thymidine, phenylalanine, and 1-naphthol (Sigma).

Apical to basolateral transport. Wells of a 12-well plate were filled with 1.2 $\mathrm{ml}$ of Ringer's solution-HEPES buffer (in mM: $150 \mathrm{NaCl}, 5.2 \mathrm{KCl}, 2.2$ $\mathrm{CaCl}_{2}, 0.2 \mathrm{MgCl}_{2}, 6 \mathrm{NaHCO}_{3}, 2.8$ glucose, 5 HEPES, pH 7.4). One insert covered by a confluent monolayer of epithelial cells was set into one well, and $0.4 \mathrm{ml}$ of the same buffer containing a known amount of $\left[{ }^{14} \mathrm{C}\right]$ sucrose and the compound or compounds of interest, either tritiated or unlabeled, was added to the upper compartment of the insert. At regular intervals thereafter, the insert was transferred to another well to minimize the backflux of molecules from the acceptor to the donor chamber. Laminin-coated filters without cells were also run in triplicate at the same time. These inserts were however transferred at shorter intervals because of the relatively high rate of flux. For $\left[{ }^{14} \mathrm{C}\right]$ sucrose and ${ }^{3} \mathrm{H}$ labeled molecules, the radioactivity of a $0.8 \mathrm{ml}$ aliquot from each well as well as a $50 \mu \mathrm{l}$ aliquot of the upper chamber was determined by liquid scintillation counting. The remaining acceptor medium and donor solution were sampled and analyzed by HPLC to determine the concentrations of the unlabeled compounds in both compartments (see below HPLC analysis).

Basolateral to apical transport. Ringer's solution-HEPES buffer (1.2 $\mathrm{ml}$ ) containing $\left[{ }^{14} \mathrm{C}\right]$ sucrose and the compound or compounds of interest was placed in one well of a 12-well plate, and an insert containing $0.4 \mathrm{ml}$ of Ringer's solution-HEPES buffer in its upper compartment was transferred to this well. At regular intervals after addition of the insert, an aliquot (whose volume could vary from 250 to $400 \mu \mathrm{l}$ ) was removed from the apical chamber and replaced with an equal volume of fresh buffer. For each sampled aliquot, a $150 \mu \mathrm{l}$ fraction was processed for liquid scintillation counting, and the remaining fraction was assayed by HPLC. As described above, triplicate filters without cells were run simultaneously.

Calculation of flux. The flux of material across the monolayer was estimated as the amount cleared from the donor fluid (SiflingerBirnboim et al., 1987). The volume clearance is given by the following equation:

$$
\text { Volume cleared }=\mathrm{C}_{\mathrm{a}} \mathrm{V}_{\mathrm{a}} / \mathrm{C}_{\mathrm{d}}
$$

where $\mathrm{C}_{\mathrm{a}}$ is the concentration in the acceptor solution at the time of sampling, $V_{a}$ is the volume of the acceptor solution, and $C_{d}$ is the concentration in the donor solution. The latter was corrected for each sampling period by adjusting its value for the amount of molecule cleared during the previous time point. This correction was essentially insignificant for small polar molecules but was important for highly lipophilic compounds such as 1-naphthol, or for measurements of compound flux across filters without cells. For apical to basolateral flux measurement, as the filter was transferred to fresh medium at each time point, the concentration in the acceptor fluid was therefore zero at the beginning of a sampling period. For basolateral to apical flux experiments, the acceptor solution was only partly sampled and renewed, and from the second to the last time point, $\mathrm{C}_{\mathrm{a}}$ was corrected to account for the amount of compound remaining from the previous sampling period.

During the course of the experiment, the clearance volume increased linearly with time, whichever direction the flux was measured. The rate of clearance, equal to the slope of a plot of the cumulative volume over time, was determined by least squares regression analysis. $C_{d}$, can be assumed constant over each sampling period. With a backflux considered as negligible, the rate of clearance becomes equal to the permeabilitysurface area (PS) product (in microliters per minute per filter). As for electrical resistances in series, the reciprocals of the PS products of the serially arranged layers composing the cell monolayer-laminin-filter system are additive (Siflinger-Birnboim et al., 1987) and verify the following equation:

$$
1 / \mathrm{PS}_{\mathrm{t}}=1 / \mathrm{PS}_{\mathrm{f}}+1 / \mathrm{PS}_{\mathrm{e}}
$$

where $\mathrm{PS}_{\mathrm{t}}$ and $\mathrm{PS}_{\mathrm{f}}$ are the PS products determined for filters with and without epithelial cells, respectively, and $\mathrm{PS}_{\mathrm{e}}$ is the permeability-surface area product of the epithelial monolayer. The permeability coefficient of the epithelial cells, Pe (centimeters per minute) was obtained by dividing the calculated $\mathrm{PS}_{\mathrm{e}}$ value by the surface area of the filter.

\section{Efflux and identification of metabolites}

The efflux of glucuronosyl conjugates from epithelial cells was determined by incubating cells with 1-naphthol or 4-methylumbelliferone applied either to the apical or the basolateral side of the monolayer at a concentration of $50 \mu \mathrm{M}$, unless otherwise specified. The acceptor compartment (respectively, the lower or the upper chamber) contained Ringer's solution-HEPES buffer and was sampled at various time points as described above. The donor solution was either sampled at regular time intervals for kinetic analysis or at the end of the experiments. Both apical and basolateral solutions were subsequently analyzed by HPLC. Export rates (in picomoles per minute per square centimeter) were obtained by dividing the total amount of glucuronide effluxed per filter by the time of the experiment. Both protocols for sampling the donor solution yielded similar results in term of export rate as the exchange of glucuronide between the two chambers was always negligible (see Results section). Identification of the glucuronosyl conjugate was conducted using $\beta$-D-glucuronidase hydrolysis as follows: $60 \mu \mathrm{l}$ of the medium sampled after cell exposure to 1-naphthol was added to $40 \mu \mathrm{l}$ of $150 \mathrm{~mm}$ acetate buffer, $\mathrm{pH} \mathrm{5}$, containing either $10 \mathrm{mg} / \mathrm{ml}$ glucuronidase (from bovine liver, $0.041 \mathrm{U} / \mathrm{mg}$; Fluka, Buchs, Switzerland), or $20 \mathrm{~mm}$ D-saccharic acid 1,4-lactone (Sigma), a specific inhibitor of glucuronidase, or both the glucuronidase and its inhibitor, and incubated for $2 \mathrm{hr}$ at $37^{\circ} \mathrm{C}$. The glucuronidase preparation being available as a thick protein suspension, proteins were precipitated at the end of the incubation by addition of $50 \mu \mathrm{l}$ of cold acetonitrile, and pelleted at $10000 \mathrm{rpm}$ for 10 min. An aliquot of the resulting supernatant was analyzed by HPLC following the protocol described below.

For isolated choroid plexus experiments, $4 \mathrm{~V}$ choroid plexuses were excised as previously described and transferred to Ringer's solutionHEPES buffer at $37^{\circ} \mathrm{C}$ for a $5 \mathrm{~min}$ recovery period. They were then incubated under agitation $(400 \mathrm{rpm})$ in a $50 \mu \mathrm{M}$ 1-naphthol solution. At regular intervals $(10,20,30$, and $40 \mathrm{~min})$, the incubation medium was recovered and replaced with fresh 1-naphthol. After the incubation, the plexuses were briefly rinsed in ice-cold Ringer's solution-HEPES buffer and digested in $1 \mathrm{~mm} \mathrm{NaOH}$ for glucuronide determination. The amount of NG present in the medium at the end of each sampling period and in the tissue at the end of the experiment was measured by HPLC. For that purpose, control choroid plexuses were incubated in parallel in the absence of 1-naphthol.

\section{HPLC analysis}

1-naphthyl- $\beta$-D-glucuronide was detected and quantified in the supernatant obtained from both UGT enzymatic activity and $\beta$-D-glucuronidase hydrolysis assay incubations by using a reverse phase HPLC procedure performed on a LC10 Shimadzu system (Duisburg, Germany) as follows: Samples $(20-50 \mu l)$ were applied with an auto injector device (SIL$10 \mathrm{Axl})$, cooled at $4^{\circ} \mathrm{C}$, onto an Ultrasphere ODS RP-18 analytical column ( $3 \mu \mathrm{m}, 4.6 \times 75 \mathrm{~mm}$; Beckman, Fullerton, CA) equipped with a RP-18 guard column. Sample elution was isocratic, using a mobile phase of a 16.5:0.5:83 mixture of acetonitrile/acetic acid/water pumped at a constant rate of $1 \mathrm{ml} / \mathrm{min}$ with a LC-10AT pump. Absorbance of the effluent was monitored at $285 \mathrm{~nm}$ using a UV variable wavelength detector (SPD10A). All chromatograms were run at room temperature. Retention times for NG and 1-naphthol were 8 and 38 min, respectively. Quantification was performed from calibration curves based on the peak areas obtained after injection of standard solutions. The detection threshold was 1 pmol for NG. For chromatogram clarity the chromatographic profiles obtained for incubations realized in the presence of glucuronidase were corrected by subtracting the profile obtained for a similar 
incubation, except that 1-naphthol was omitted in the original cultured cell incubation.

The subsequent routine quantification of 1-naphthol and of its glucuronosyl-conjugate in the Ringer's solution-HEPES buffer incubation medium was realized by direct injection of the samples into the HPLC apparatus, using similar analytical condition except that a mobile phase of a 22:0.5:77.5 mixture of acetonitrile-acetic acid-water was used to reduce the retention time of NG and 1-naphthol to 3.5 and $20 \mathrm{~min}$, respectively. Experiments using 4-methylumbelliferone as substrate were realized and quantified in a similar way, except that the detector was set at $317 \mathrm{~nm}$, and the mobile phase used was a 14.5:0.5:85 mixture of acetonitrile-acetic acid-water, leading to retention times of 2.4 and 10 min for 4-methylumbelliferyl- $\beta$-D-glucuronide and 4-methylumbelliferone, respectively. For thymidine transfer experiment, the HPLC quantification of the compound was realized by direct injection of incubation medium onto a TSK gel super ODS column (Tosohaas, Montgomeryville, PA). With the UV detector set at $266 \mathrm{~nm}$ and an isocratic elution using a 3.5:76.5 mixture of acetonitrile-water as the mobile phase, the retention time for thymidine was $3.6 \mathrm{~min}$. For each set of transfer experiments, one filter was run in the same manner, except that the compound studied was omitted from the cell incubation system. The collected apical and basolateral media were then analyzed by HPLC to check that no material, possibly released from the filter/cell system, coeluted with the compounds investigated or their metabolites.

\section{Effect of temperature on NG efflux}

Epithelial cells were incubated with $20 \mu \mathrm{M}$ 1-naphthol in the apical chamber and allowed to accumulate the corresponding glucuronide for $20 \mathrm{~min}$ at $37^{\circ} \mathrm{C}$. Monolayers were then washed extensively in ice-cold Ringer's solution-HEPES buffer until the remaining substrate was fully eliminated, as monitored by HPLC analysis of the washing solutions, and further incubated with fresh buffer in both compartments either for $2 \times$ $10 \mathrm{~min}$ at $4^{\circ} \mathrm{C}$ or $37^{\circ} \mathrm{C}$ or for $10 \mathrm{~min}$ at $4^{\circ} \mathrm{C}$ followed by $10 \mathrm{~min}$ at $37^{\circ} \mathrm{C}$. The efflux of the metabolite was quantified in both chambers by HPLC.

\section{Probenecid-sensitivity of NG efflux}

Cells were exposed apically to $50 \mu \mathrm{M}$ 1-naphthol as a substrate and NG efflux was monitored in both chambers. Probenecid (dissolved in DMSO) was added to both compartments, and its possible effect on the monolayer tightness was assessed by measuring apical to basolateral transfer of $\left[{ }^{14} \mathrm{C}\right]$ sucrose. Control experiments were run using DMSO alone. Wells of a 12-well plate were filled with $1.2 \mathrm{ml}$ of Ringer's solution-HEPES containing probenecid or DMSO. Inserts covered with cells were set into wells, and $0.4 \mathrm{ml}$ of buffer containing $\left[{ }^{14} \mathrm{C}\right]$ sucrose, 1-naphthol, and probenecid or DMSO (donor solution) was added to the upper compartment of the inserts. At 20 and $40 \mathrm{~min}$, the insert was transferred to another well. Simultaneously, the $400 \mu \mathrm{l}$ upper solution was removed and replaced with an equal volume of fresh donor solution. Aliquots of the lower chamber were radioassayed for $\left[{ }^{14} \mathrm{C}\right]$ sucrose as described above. Samples from both chambers were analyzed by HPLC. At the end of the efflux experiment (time $60 \mathrm{~min}$ ), the cells were washed by two quick immersions in a large volume of ice-cold Ringer's solution-HEPES buffer, followed by two 5 min incubations in ice-cold buffer on a rocking platform. Membranes were cut from the inserts, and cells were lysed by freeze-thaw cycles in $100 \mu \mathrm{l}$ distilled water. Proteins were precipitated by $70 \mu \mathrm{l}$ acetonitrile and centrifuged. The supernatant was recovered, and the intracellular NG was assayed by HPLC as described above.

\section{Competition experiments}

Epithelial cell monolayers were loaded with the glutathione $S$-conjugate, 2,4-dinitrophenyl glutathione (GS-DNP) by apical exposure to $1 \mathrm{~mm}$ CDNB for $10 \mathrm{~min}$ at $37^{\circ} \mathrm{C}$, followed by a $15 \mathrm{~min}$ period at $18^{\circ} \mathrm{C}$. This second period enables to reach an appreciable pool of competitor within the cells as it reduces transport of GS-DNP out of the cells without reducing the GS-DNP formation rate (Lam et al., 1992; Evers et al., 1996). After loading, each filter was positioned in a 12-well plate containing $1 \mathrm{ml}$ of Ringer's solution-HEPES buffer in each well, and the apical medium was replaced with $0.3 \mathrm{ml}$ of the donor solution containing $1 \mathrm{~mm}$ CDNB, $20 \mu \mathrm{M}$ 1-naphthol, and $\left[{ }^{14} \mathrm{C}\right]$ sucrose. NG efflux was monitored in both chambers as described above, except that the volume sampled and replaced in the upper chamber at each interval was $150 \mu \mathrm{l}$. The intracellular amount of NG was determined as described above. Control filters were incubated in parallel with $0.25 \%$ ethanol instead of CDNB.

\section{RESULTS}

\section{Rat CPE cells in primary culture form a polarized monolayer on laminin-coated filters}

In addition to the morphological differences between choroid plexuses from the lateral, third, and fourth ventricles, biochemical differences were also reported (Strazielle and Ghersi-Egea, 1997b). Separate primary cultures of epithelial cells were therefore initiated from plexuses harvested from LV and $4 \mathrm{~V}$. Because the characteristics and properties investigated in this study were similar for both types of culture, results will be presented only for one type of cell or the other. Cells were prepared according to Tsutsumi et al. (1989), by which isolation of epithelial cells versus other types of cell is achieved by differential sedimentation and attachment. The mild enzymatic dissociation step yielded a final epithelial cell suspension comprising only a few single cells and mainly small cell clusters. Therefore, accurate cell counting was not feasible, and the cell suspension was plated on a surface area per choroid plexus basis. This cell dilution procedure gave consistent results with regard to the course of establishment of optical confluence and barrier properties. Cell attachment on laminin-coated filters occurred within 24-36 hr and was complete after $48 \mathrm{hr}$, at which time the media was changed. The cells achieved optical confluence within 2-3 d after plating. They grew as densely packed small polygonal cells and produced a monolayer displaying a typical cobblestone appearance (Fig. 1A).

Choosing the appropriate substrate used to reconstitute a basement membrane was found to be a crucial step for achieving the further selection of epithelial cells. When plated on collagencoated filters, cells failed to establish the hydrodynamic barrier that they formed on laminin-coated filters (see below), and inverse phase optical microscopy revealed the presence of clusters of fibroblast-like elongated cells that tended to overgrow the epithelial cells (Fig. $1 B$ ). These contaminating cells were not observed on laminin-coated filters (Fig. $1 A$ ), even after extended periods of culture (up to $12 \mathrm{~d}$ ). Coating of Transwell-COL (already precoated with collagen by the manufacturer) with laminin did not improve the selectivity or the establishment of the barrier phenotype (data not shown).

The epithelial phenotype of the cells was further demonstrated by positive staining with a mixture of anti-cytokeratin monoclonal antibodies that recognize among others the simple epithelial types of keratins $(8,18$, and 19) known to be expressed in vivo in the CPE cells (Miettinen et al., 1986; Fig. 1E). Variation in fluorescence intensity among the cell population is likely to reflect the differential expression of the various cytokeratin subtypes.

The 1- $\mu \mathrm{m}$-thin cross-sections confirm that after $8 \mathrm{~d}$ of culture on laminin-coated filters, the cells formed a monolayer of bulging cuboidal cells with morphological asymmetry (Fig. 1C). In particular, the dome-shaped apical surface was studded with microvilli extending upward into the medium (Fig. 1D).

Transmission electron microscopy was performed to confirm the extent to which cells in culture displayed ultrastructural features characteristic of the cells in situ. Eight-day-old monolayers displayed cuboidal cells with distinct cell surface domains. At the luminal or apical surfaces, the cells presented uneven borders of thin cytoplasmic processes resembling tightly packed elongated microvilli (Fig. 2A). Intercellular junctional complexes were observed at the apical end of the lateral faces of contiguous cells as electron dense areas (Fig. 2B), closely mimicking the zonula adherens and zonula occludens organization observed in the 

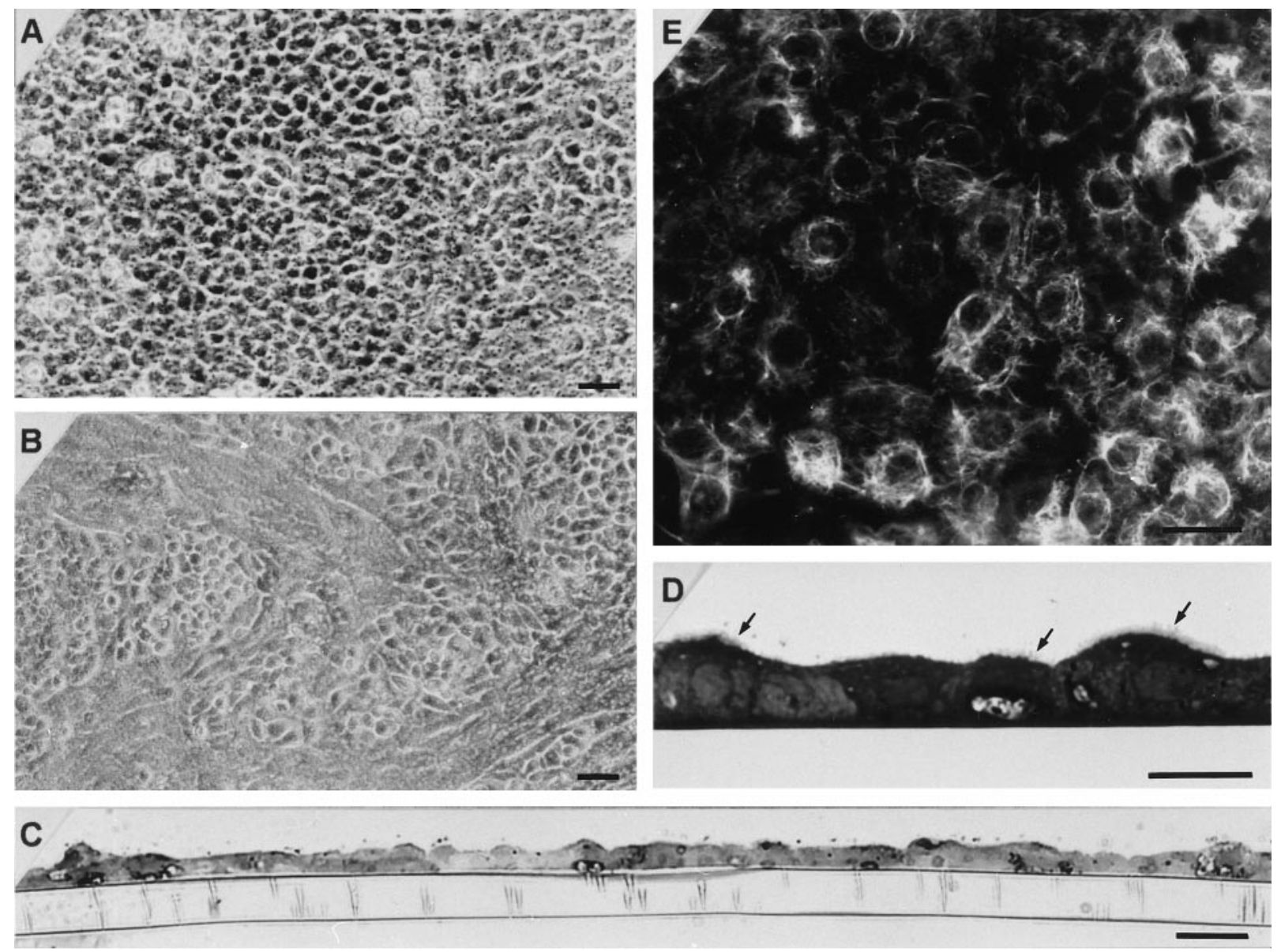

Figure 1. Morphology and phenotype of primary culture of rat CPE cells. Phase-contrast micrographs of 8-d-old CPE cells cultured on laminin-coated filters $(A)$ shows a typical cobblestone arrangement of polygonal cells, whereas a heterogeneous cellular population that includes fibroblast-like elongated cells is observed when rat tail collagen-coated filters are used $(B)$. The light micrograph of a 1- $\mu$ m-thick cross section $(C)$ shows a confluent 8 -d-old monolayer of CPE cells lying on the laminin-coated permeable filter. Higher magnification of CPE cell monolayer $(D)$ illustrates the presence of numerous microvilli (arrows) decorating the apical cell surface. The immunofluorescence assay using anti-cytokeratin antibodies ( $E$ ) shows a positive staining of the cells. Scale bars: $A-C, 20 \mu \mathrm{m} ; D, E, 10 \mu \mathrm{m}$.

CPE cells in situ (data not shown; Peters et al., 1991). Beneath these junctions, the plasma membranes of these lateral cell surfaces ran more or less parallel to each other, extending near the basal region, in extensive interdigitations forming characteristic complex infoldings (Fig. 2C).

\section{CPE cells develop functional barrier properties and establish intercellular tight junctions}

An essential feature of the choroidal epithelium in vivo is the formation of a semipermeable barrier to the passage of solutes, that is based on sealing apical tight junctions between neighboring epithelial cells. The in vitro establishment of barrier properties can be tested by monitoring transepithelial electrical resistance of cells cultured on permeable supports and by measuring the paracellular (intercellular) flux of small molecular weight hydrophilic tracers. Therefore, TEER and the clearance of sucrose were measured in parallel from the first day of culture to up to day 8 and were used as evidence for the development of functional tight junctions in the monolayers. With cell optical confluence at day 2, TEER across the cell layers became significantly higher than the resistance measured on laminin-coated filters and rapidly increased until it reached a plateau around day 6 (Fig. $3 A$ ). The value of $178 \Omega \times \mathrm{cm}^{2}$ at day 8 is similar to the TEER measured in vivo in bullfrog choroid plexus (Saito and
Wright, 1983). Permeability to sucrose was inversely related to the electrical resistance and was gradually impeded, to reach at day 8 , a $\mathrm{P}_{\mathrm{e}}$ value of $0.43 \times 10^{-3} \pm 0.02 \times 10^{-3} \mathrm{~cm} / \mathrm{min}$ (Fig. $3 B$ ). Consistent with the establishment of intercellular junctions, this value increased dramatically to $12.07 \times 10^{-3} \pm 2.21 \times 10^{-3}$ $\mathrm{cm} / \mathrm{min}$ when sucrose flux was measured in the absence of extracellular $\mathrm{Ca}^{2+}$ and $\mathrm{Mg}^{2+}$, that are required for junction integrity. Indicative of an insignificant fibroblast contamination in the monolayer, neither cis-hydroxyproline, nor cytosine $\beta$-D-arabinofuranoside, when added to the culture medium as classical inhibitors of fibroblast growth, decreased the flux of sucrose across the monolayer (data not shown).

Furthermore, CPE cells generated a hydrodynamic barrier as early as day 2 after seeding (Fig. $3 C$ ). Volumes of medium added in both chambers on that day were such as to create a difference in fluid levels, the level being higher in the upper reservoir, to generate a hydrodynamic pressure. CPE cell monolayers were able to maintain this hydrodynamic imbalance for the next $48 \mathrm{hr}$, and for each interval of time between later medium renewals. In contrast, CPE cell monolayers cultured on collagen filters and containing fibroblast-like cells, or filters covered with fibroblasts at high density, failed to maintain this hydrodynamic difference, which was dissipated in $<12 \mathrm{hr}$ (overnight). 
Figure 2. Ultrastructure of newborn rat CPE cells cultured on laminin-coated filters. Transmission electron micrographs of cultured CPE cells demonstrate the ultrastructural features of a polarized epithelial cell monolayer such as an abundant border of elongated microvilli associated with the apical surface (top panel; scale bar, $0.5 \mu \mathrm{m}$ ), tightly apposed lateral membrane with complex apical junctions organized as zonula adherens and zonula occludens association (arrow), and gap junction (arrowhead) (bottom left panel; scale bar, $0.25 \mu \mathrm{m})$, and complex interdigitations $(\star)$ at the basolateral side (bottom right panel; scale bar, $0.25 \mu \mathrm{m}$ ). $F$, Porous filter.
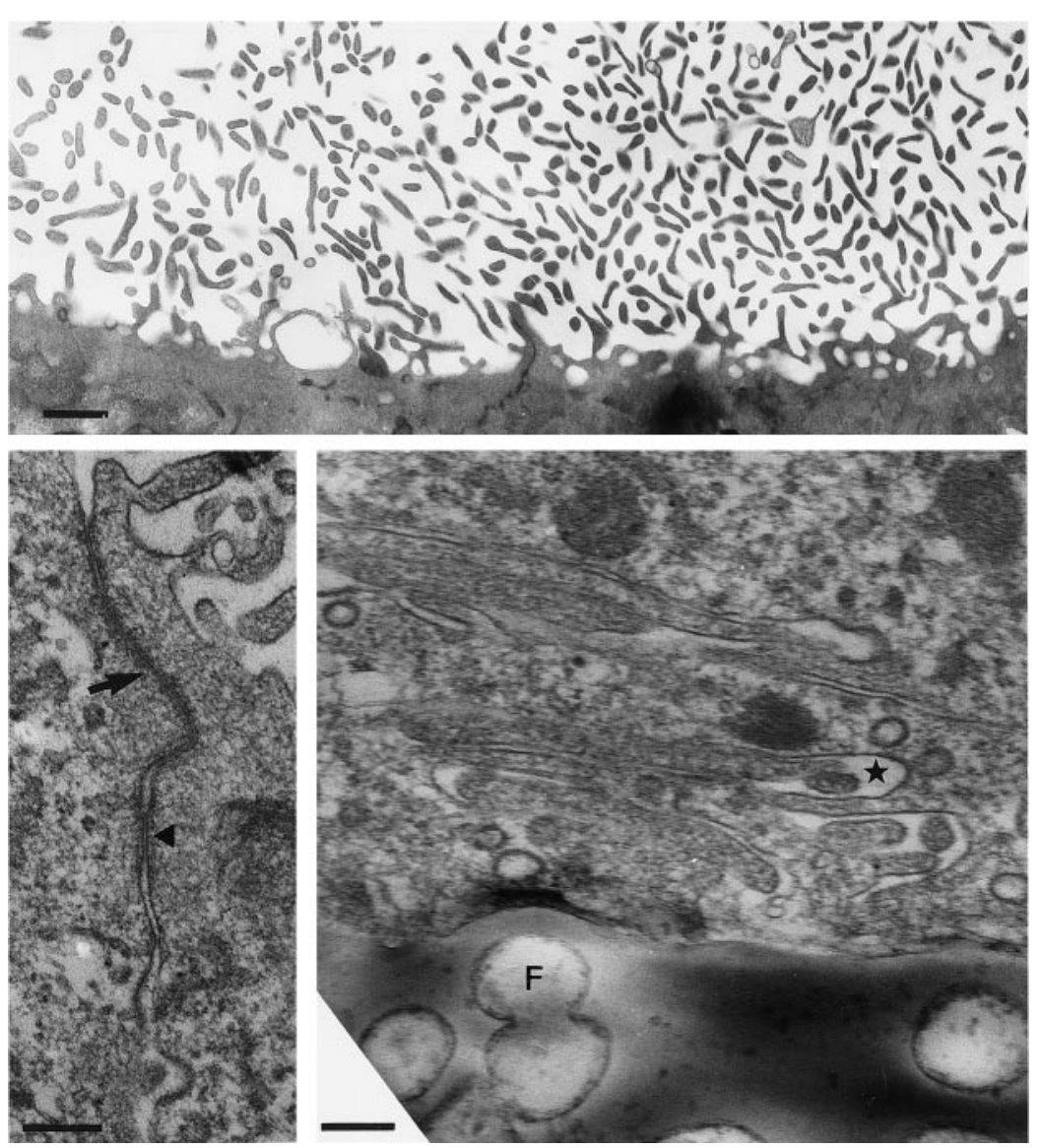

The intercellular junctional structures, that are crucial for the epithelium to generate electrical gradients and regulate its permeability, are complex and include transmembrane proteins interacting with cytoplasmic partners and with the cytoskeleton. In particular, the transmembrane protein occludin, exclusively localized at tight junctions in epithelia, has been demonstrated to contribute to the paracellular seal and interact indirectly via ZO-1 with an adjacent perijunctional ring of actin, that also regulates the tight junction permeability (Fanning et al., 1998). Both occludin and actin intracellular distribution was investigated in 8-d-old CPE cell monolayers. Staining with phallacidin showed a marginal arrangement of actin filaments, consistent with a continuous belt lining the cell membrane (Fig. 4A). In a similar pattern, an anti-occludin antibody stained a junctional ring with no apparent discontinuities (Fig. $4 B$ ). Both markers confirmed the establishment in CPE cell primary cultures of tight junctions previously suggested ultrastructurally by EM and functionally by TEER and sucrose permeability data.

\section{CPE cell monolayers express the choroidal specific protein transthyretin and retain transport systems}

Brain transthyretin is mostly synthesized and secreted by the epithelial cells of the choroid plexus, for which it is regarded as a tissue-specific and differentiation marker (Kato et al., 1986). Transthyretin mRNA expression was investigated in cultured CPE cells by reverse PCR, in comparison to freshly isolated choroid plexuses from newborn rat (Fig. 5). After 3 and $8 \mathrm{~d}$ of culture, epithelial cells from the lateral ventricle choroid plexus continued to express transthyretin mRNA demonstrating the highly differentiated status of the in vitro choroidal epithelium. Northern blot analysis was performed using as a cDNA probe, the fragment amplified by PCR. It was also confirmed that $4 \mathrm{~V} \mathrm{CPE}$ also retained this specificity and marker of differentiation, and that in both types of cultured cells, messenger levels are maintained at equivalent levels during the course of the culture (data not shown). In vitro uptake studies using isolated/perfused choroid plexuses and some in vivo experiments have shown that carrier-mediated transport of amino acids and nucleosides takes place at the choroid plexus (Spector, 1985; Segal et al., 1990; Thomas and Segal, 1996). The ability of the epithelial barrier to transport such compounds was examined on 8-d-old CPE cell monolayers (Table 1). 4V CPE cells were exposed on the basolateral side to phenylalanine at a low concentration of $2 \mu \mathrm{M}$. The permeability measured was much higher than that of sucrose. Furthermore, increasing the concentration of phenylalanine to $500 \mu \mathrm{M}$ reduced significantly the cell monolayer permeability to the amino acid by $>60 \%$. These results are consistent with a saturable carrier-mediated transport of the amino acid. Selfinhibition of thymidine transport also was demonstrated on LV CPE cells with a significant decrease of $35 \%$ in the Pe value between 5 and $800 \mu \mathrm{M}$.

\section{The high drug metabolism activity of choroid plexus is maintained in cultured CPE cells}

The elevated metabolic capacity toward xenobiotics that is characteristic of choroidal tissue was evaluated in the in vitro model. Drug metabolism classically involves phase I enzymes, which create or modify a functional group on a generally lipophilic substrate and phase II enzymes, which conjugate the functional group of xenobiotics or of their primary metabolites with various polar cosubstrates. The specific activity of two phase I enzymes, the membrane-bound epoxide hydrolase and NADPH cytochrome 

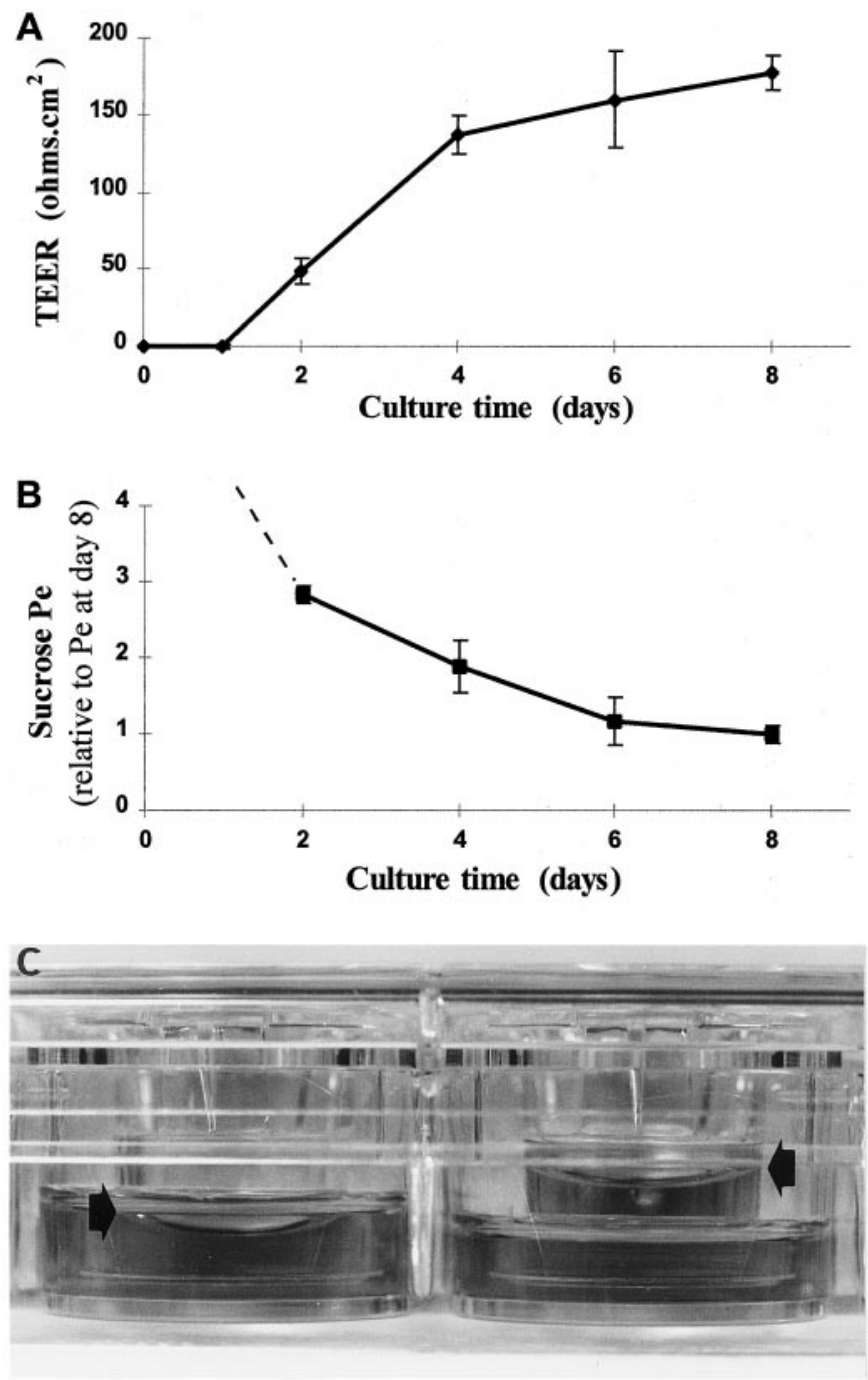

Figure 3. Establishment of barrier properties by cultured CPE cells. $A$, Development of transepithelial resistance in LV CPE cell monolayer. Note the marked increase in electrical resistance between days 2 and 6 . Values are expressed as mean \pm SD obtained from four different filters and are corrected for the mean electrical resistance of four laminincoated filters. $B$, Development of a permeability barrier in LV CPE cell monolayer. Apical to basal flux of $\left[{ }^{14} \mathrm{C}\right]$ sucrose was measured for $60 \mathrm{~min}$. Pe values are expressed relative to Pe at day 8 , as mean \pm SD obtained from four different filters. Pe decreased as a function of culture time. The Pe measured on 8-d-old cultured cells raised from $0.43 \times 10^{-3} \pm 0.02 \times$ $10^{-3} \mathrm{~cm} / \mathrm{min}$ when the transfer experiment was performed in standard condition to $12.1 \times 10^{-3} \pm 2.2 \times 10^{-3} \mathrm{~cm} / \mathrm{min}$ when the transfer experiment was performed in $\mathrm{Ca}^{2+} / \mathrm{Mg}^{2+}$-free buffer that disrupts the tight junction organization. $C$, Generation of a hydrodynamic barrier at day 2 . When culture medium is changed on the second day after plating, CPE cell monolayers on laminin-coated supports (filter on the right) impede, during the next $48 \mathrm{hr}$, the hydrodynamic equilibration of fluids between the two chambers, unlike CPE cells on collagen-coated filters or optically confluent filters seeded with fibroblasts (filter on the left).

$\mathrm{P}-450$ reductase, and two phase II enzymes, UGT and glutathione $S$-transferase (GST), were measured in 7- to 9-d-old LV and 4V CPE cells, in comparison to freshly isolated plexuses, as well as in liver and cerebral cortex from newborn rat (Fig. 6). For all the enzymes, the activity was maintained in the cultured epithelial cells, at levels not significantly different from those measured in the corresponding freshly isolated plexuses. These activities are comparable to the levels measured in the liver, which is the major

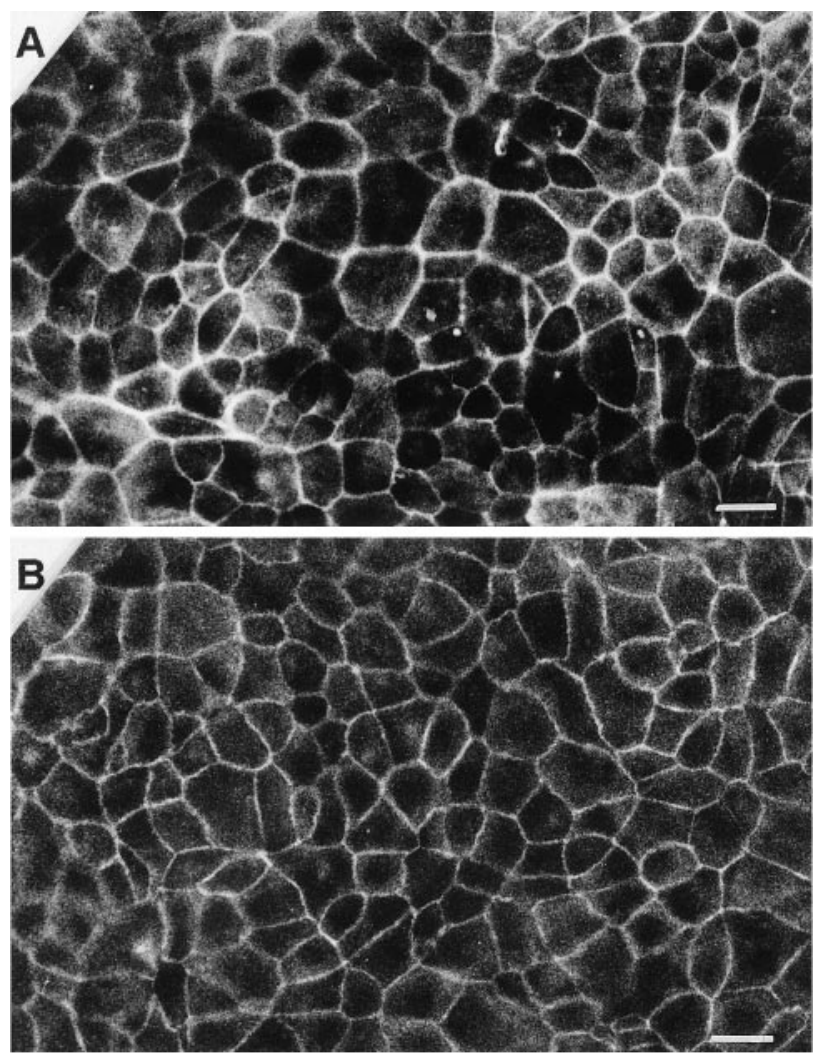

Figure 4. Distribution of junction-associated proteins in cultured CPE cells. Eight-day-old CPE cells grown on laminin-coated filters were labeled with phallacidin for actin staining $(A)$ or with antibodies against occludin $(B)$. Both markers showed a continuous circumferential distribution consistent with the establishment of tight junctions in CPE cell monolayers. Scale bar, $10 \mu \mathrm{m}$.

organ responsible for drug metabolism, and, with the exception of NADPH cytochrome P-450 reductase activity, which is high in brain tissue at early developmental stages (Ghersi-Egea et al., 1989), are 7- to 30-fold higher than in the overall cortex. These data indicate that (1) the xenobiotic metabolism capacity of choroid plexus is at least for a large part attributable to the choroidal epithelium, although other cells from the stromal core could also contribute to this function, and (2) CPE cells after $8 \mathrm{~d}$ in culture retain this drug metabolism specificity.

\section{The choroid epithelium forms an effective metabolic barrier through conjugation pathway}

The in situ metabolic capacity of cultured epithelial cells and its possible implication and consequences on xenobiotic transfer through the monolayer was investigated using 1-naphthol, a cytotoxic compound which is used as a model of lipid soluble substrate.

As expected from its strong lipophilicity (indicated by an octanol/pH 7.4 buffer partition coefficient of 248) (B. LeiningerMuller, personal communication), 1-naphthol diffused readily across the choroidal monolayer, with a clearance rate considerably higher than that of sucrose. In the experiment illustrated in Figure $7 A$, apical to basolateral $\mathrm{PS}_{\mathrm{t}}$ values were $6.85 \pm 0.36$ and $0.46 \pm 0.07 \mu \mathrm{l} \cdot \mathrm{min}^{-1} \cdot$ filter $^{-1}$ for $50 \mu \mathrm{M}$ 1-naphthol and for sucrose, respectively. The process was linear over the time period studied (60 min) and was independent of the direction of transfer as a similar plot could be obtained for basolateral to apical transfer (data not shown). When 1-naphthol was used at a con- 


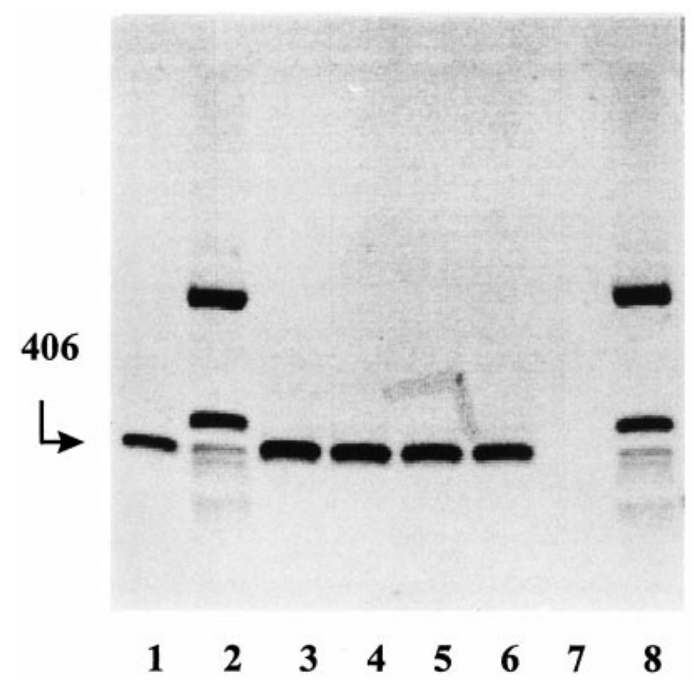

Figure 5. Expression of transthyretin in CPE cells. Total mRNA preparations isolated from newborn rat 4V (lane 3) and LV (lane 4) choroid plexuses, 3-d-old LV CPE cells (lane 5), and 8-d-old LV CPE cells (lane $6)$ were reverse transcribed with oligo-dT. The 406-bp-long fragment amplified using oligonucleotides specific for transthyretin in samples from both fresh tissue and cellular cultures shows that transthyretin mRNA expression is maintained in cultured cells. Newborn rat liver mRNA (lane 1) and cultured glial cells mRNA (lane 7) were processed in parallel as positive and negative control, respectively. Lanes 2 and 8 contain DNA molecular weight markers.

$\overline{\text { Table 1. Basolateral to apical saturable transport of }\left[{ }^{3} \mathrm{H}\right] \text { phenylalanine }}$ and $\left[{ }^{3} \mathrm{H}\right]$ thymidine across CPE cell monolayers

\begin{tabular}{lll} 
Phenylalanine concentration & Phenylalanine & Sucrose \\
\hline $2 \mu \mathrm{M}$ & $2.79 \pm 0.20$ & $0.34 \pm 0.02$ \\
$500 \mu \mathrm{M}$ & $1.02 \pm 0.03^{*}$ & $0.35 \pm 0.04$ \\
$\quad$ Means $\pm \mathrm{SD}, n=4$ & &
\end{tabular}

\begin{tabular}{lll} 
Thymidine concentration & Thymidine & Sucrose \\
\hline $5 \mu \mathrm{M}$ & $0.69 \pm 0.02$ & $0.35 \pm 0.02$ \\
$800 \mu \mathrm{M}$ & $0.45 \pm 0.02^{*}$ & $0.34 \pm 0.02$ \\
$\quad$ Means $\pm \mathrm{SD}, n=3$ & &
\end{tabular}

The basolateral to apical transport of phenylalanine and thymidine across 8-d-old $\mathrm{CPE}$ cells was measured by incubating the cells with either $2 \mu \mathrm{M}\left[{ }^{3} \mathrm{H}\right]$ phenylalanine or $5 \mu \mathrm{M}\left[{ }^{3} \mathrm{H}\right]$ thymidine in the basolateral chamber with or without a high concentration of cold compound. The apical compartment was sampled repeatedly for 60 min, and permeability coefficients $\mathrm{P}_{\mathrm{e}}$ (in $10^{-3} \mathrm{~cm} / \mathrm{min}$ ) were generated. The epithelial permeability to $\left[{ }^{14} \mathrm{C}\right]$ sucrose was determined simultaneously on all filters as an index of paracellular passage across the monolayer. *Statistically different from low concentration, $p<0.01$, one tailed $t$ test for unequal variance.

centration of $50 \mu \mathrm{M}$, the permeability coefficients Pe were calculated to be $12.55 \times 10^{-3} \pm 4.88 \times 10^{-3} \mathrm{~cm} / \mathrm{min}$ and $12.95 \times$ $10^{-3} \pm 1.82 \times 10^{-3} \mathrm{~cm} / \mathrm{min}(n=4)$ for basolateral to apical and apical to basolateral transfer, respectively.

When cells were incubated with decreasing concentrations (10, $5,2$, and $1 \mu \mathrm{M})$ of the lipophilic molecule in the basolateral chamber, the clearance of the compound was strongly reduced, leading to an almost complete inhibition of 1-naphthol diffusion in the opposite chamber for concentration $<2 \mu \mathrm{M}$ (Fig. 7B). Indeed, the permeability coefficient calculated for $1 \mu \mathrm{M}$ 1-naphthol was $0.35 \times 10^{-3} \pm 0.24 \times 10^{-3} \mathrm{~cm} / \mathrm{min}(n=5)$, and was not statistically different from that of sucrose $\left(0.49 \times 10^{-3} \pm\right.$ $0.07 \times 10^{-3} \mathrm{~cm} / \mathrm{min}$ ) whose transfer rate was measured simulta- neously as an indicator of paracellular pathway. As indicated by the linearity of the clearance curve obtained for $1 \mu \mathrm{M}$ 1-naphthol (Fig. $7 A$ ), the barrier effect occurred immediately and could not be accounted for by 1-naphthol depletion because our experimental conditions ensured that $<10 \%$ of the initial amount of 1-naphthol was cleared from the donor chamber by the end of the sampling period.

Based on these results, it was postulated that epithelial cell drug metabolizing enzymes could actually form an enzymatic barrier to xenobiotic flux, which thus implied the intracellular production of metabolites and their eventual excretion either at one or at both poles of the polarized cells. Because 1-naphthol is substrate for the UGT isoform that conjugates planar phenols, the glucuronosyl conjugate of this compound was primarily investigated in both apical and basolateral transfer solutions. The analysis of HPLC elution profiles revealed in samples collected from either chamber a peak that was not present when transfer of 1-naphthol was performed on filter without cells, and had a retention time identical to that of NG (Fig. 8, compare $A, B$ ). The identity of the compound released from CPE cells was further assessed by its susceptibility to $\beta$-glucuronidase cleavage. Incubating the transfer solution with $\beta$-glucuronidase led to a complete disappearance of the signal, whereas in parallel incubations realized in absence of $\beta$-glucuronidase, this peak remained unchanged (Fig. $8 B, C$ ). To confirm the specificity of a $\beta$-glucuronidase-mediated cleavage of the compound, similar glucuronidase incubations were performed in the presence of $20 \mathrm{~mm}$ D-saccharic acid 1,4-lactone, a specific inhibitor of the enzyme. The persistence of the peak eluted at 8 min (Fig. 8D) demonstrated that the compound released by $\mathrm{CPE}$ cells was indeed generated by glucuronidation.

\section{Export of glucuronosyl conjugates by CPE cells is a transporter-mediated polarized process}

Because CPE cells form a tight monolayer delimiting two separate compartments, it became possible to investigate the kinetic of NG export across each membrane. The inset in Figure $9 A$ illustrates as an example, the time course of NG efflux from $4 \mathrm{~V} \mathrm{CPE}$ cell monolayers exposed on both membranes to $50 \mu \mathrm{M}$ 1-naphthol, and shows that the export of the metabolite was linear and occurred immediately in both chambers. However, a striking difference in the curve slopes was observed. The basolateral and apical export rate values calculated from repeated experiments were of $16.88 \pm 2.72$ and $6.51 \pm 1.25 \mathrm{pmol} \cdot \mathrm{min}^{-1} \cdot \mathrm{cm}^{-2}$, respectively ( $n=10$ filters from four cell preparations; Fig. 9A). Because the apical membrane of CPE cells has a brush-border of microvilli, it is likely to present a much larger surface area available for exchange than the basolateral membrane. Therefore, the $2.63 \pm 0.35$-fold higher secretion of the glucuronide in the bottom chamber indicates a strongly polarized process, resulting in preferential metabolite elimination at the blood-facing membrane. A similar cell polarity was observed on LV CPE cell monolayers with a basolateral to apical ratio of $2.66 \pm 0.49(n=$ 5 filters from two cell preparations) for the glucuronide efflux.

As a further evidence of polarity, Figure $9 B$ shows that NG was produced by isolated choroid plexuses and released in the incubation medium, but in contrast to the export kinetic observed on CPE cell monolayers, this release was nonlinear and increased significantly during the first three sampling periods, coming to a plateau between 30 and $40 \mathrm{~min}$. Moreover, a large amount of NG was retained in the tissue, most likely in the stromal compartment delineated by the tight choroidal epithelium rather than intracellularly (see below for intracellular amount of NG in the cultured 

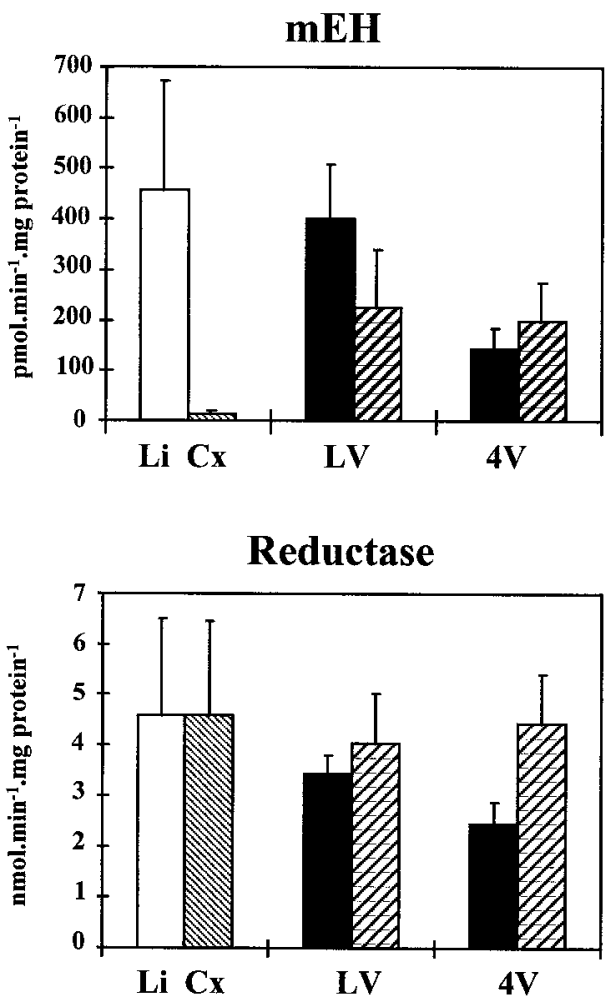
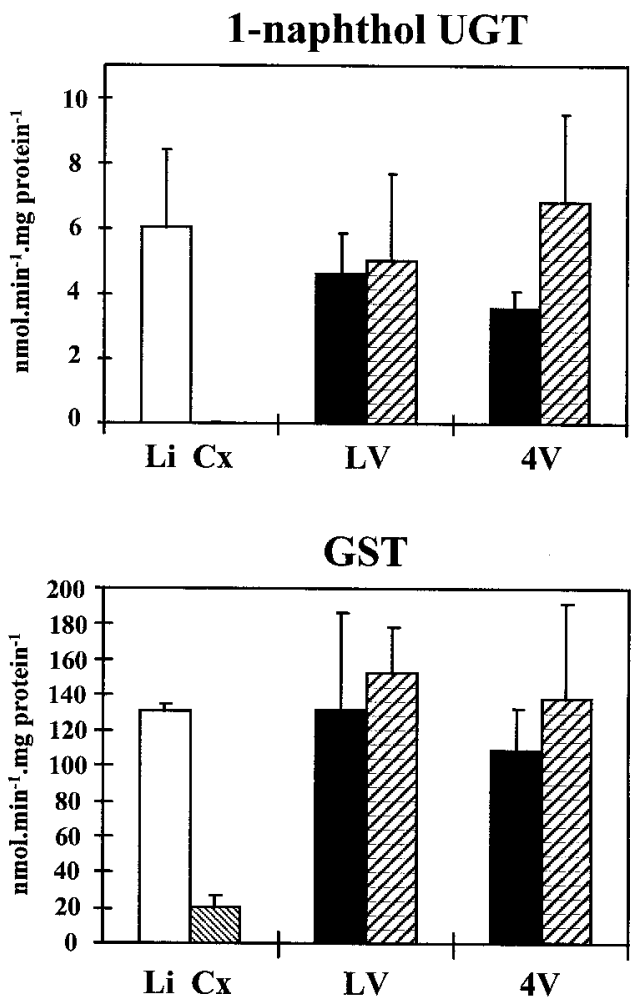

Figure 6. Xenobiotic metabolism enzyme activities in CPE cells. Homogenates of freshly isolated choroid plexuses (solid columns) and CPE cells cultured for $8 \mathrm{~d}$ (dashed columns) from either lateral ventricle $(L V)$ or fourth ventricle $(4 \mathrm{~V})$ were assayed for four drug-metabolizing enzyme activities: the membrane-bound epoxide hydrolase $(m E H)$, UDP-glucuronosyltransferase-conjugating planar substrates (1naphthol UGT), NADPH cytochrome P-450 reductase (Reductase), and glutathione $S$-transferase $(G S T)$. For comparison, activities measured in freshly isolated liver $(L i)$ and cerebral cortex $(C x)$ homogenates are also reported. All four activities measured in cultured cells were close to those measured in fresh choroidal tissue and reached hepatic levels. Note the large, statistically significant (two-tailed $t$ test for unequal variance) differences in the level of $\mathrm{mEH}, 1$-naphthol UGT, and GST activities when any choroidal material was compared with cerebral cortex. Data are expressed as mean $\pm \mathrm{SD} ; n=3-7$. cells). This data, and the delay in reaching a steady-state efflux rate in the incubation medium are in favor of a preferential basolateral export of $\mathrm{NG}$, i.e., into the stromal compartment of the isolated choroid plexus, before its release in the incubation medium.

As this polarized efflux is indicative of a transporter-mediated mechanism rather than a passive diffusion process, the temperature-dependence of $\mathrm{NG}$ efflux was investigated. CPE cells loaded with $\mathrm{NG}$ and maintained at $37^{\circ} \mathrm{C}$ rapidly exported the metabolite in the incubation medium (Fig. 10). The efflux was almost fully inhibited when cells were kept at $4^{\circ} \mathrm{C}$ (with a respective inhibition of 100 and $92 \%$ for the two efflux periods). When cells kept at $4^{\circ} \mathrm{C}$ for 10 min were rewarmed to $37^{\circ} \mathrm{C}$, NG efflux resumed immediately and was comparable to that of cells kept at the higher temperature. By contrast, decreasing the temperature from 37 to $4^{\circ} \mathrm{C}$ led to a reduction of only 3.8- and 3.3-fold in respective $\mathrm{PS}_{\mathrm{t}}$ values for sucrose (as a paracellular marker) and 1-naphthol (used as a model molecule for the passive diffusion process; data not shown). The total inhibition of NG export is thus further evidence for a transport process.

To assess whether the membrane transport process was unidirectional or bidirectional, we measured the passage of extracellularly added NG across the cell monolayer in both directions (Table 2). The permeability of CPE cells to the glucuronide was always slightly lower than that of sucrose, whichever membrane was exposed to the molecules ( $p<0.01$, paired $t$ test). No statistical differences in glucuronide Pe values were found either between the low and high concentrations of NG or between the two transfer directions. These data indicate that (1) NG is not lipophilic enough to passively cross the membranes to a significant extent (as predicted for a glucuronosyl conjugate), and (2) the polarized NG efflux we demonstrated is unidirectional and outwardly directed, i.e., mediated by an active transport rather than a facilitated diffusion process.
The apparent affinity of this metabolism-efflux process for 1-naphthol was then investigated. Varying the concentration of 1-naphthol in the medium from 500 to $1 \mu \mathrm{M}$ changed neither the rate of glucuronide production nor the polarity of efflux (data not shown). Only for a concentration of $0.4 \mu \mathrm{M}$ was the efflux rate decreased by $21.2 \pm 12.8 \%(n=3)$, without change in the polarity. Lower concentrations could not be tested as the substrate was cleared too fast for the extracellular concentration to remain constant over the sampling period. Therefore, with an apparent affinity constant $<0.4 \mu \mathrm{M}$, the overall affinity of the metabolism-efflux process occurring at the cultured cell monolayer is rather high for 1-naphthol and explains the total barrier effect observed when 1-naphthol concentration was $<2 \mu \mathrm{M}$ (see Discussion). The apparent affinity constant of UGT toward 1-naphthol, determined on newborn rat choroid plexus homogenate, was found to be $1.6 \mu \mathrm{M}$ (data not shown). This value is slightly higher than the apparent affinity constant measured for the metabolism-efflux of NG in CPE cells, a difference that could be accounted for by a moderate concentration of the substrate in the cells. Indeed, assuming an average cell height of $8 \mu \mathrm{m}$, the intracellular concentration of 1-naphthol at the end of the experiments was estimated to be fivefold to eightfold higher than the actual 1-naphthol concentration used in the incubation medium (data not shown).

\section{Export of NG by CPE cells is probenecid-sensitive and is shared by other conjugates}

The substrate specificity of the transporter involved in NG efflux was tested toward a different glucuronosyl conjugate. For that purpose, 4V CPE cells were exposed to $50 \mu \mathrm{M}$ 4-methylumbelliferone, another UGT substrate, and the efflux rate of the corresponding metabolite 4-methylumbelliferyl- $\beta$-D-glucuronide, was determined in both compartments. Basolateral and apical export rate values were, respectively, $6.94 \pm 0.60$ and $2.18 \pm 0.12 \mathrm{pmol} \cdot \mathrm{min}^{-1} \cdot \mathrm{cm}^{-2}$ 

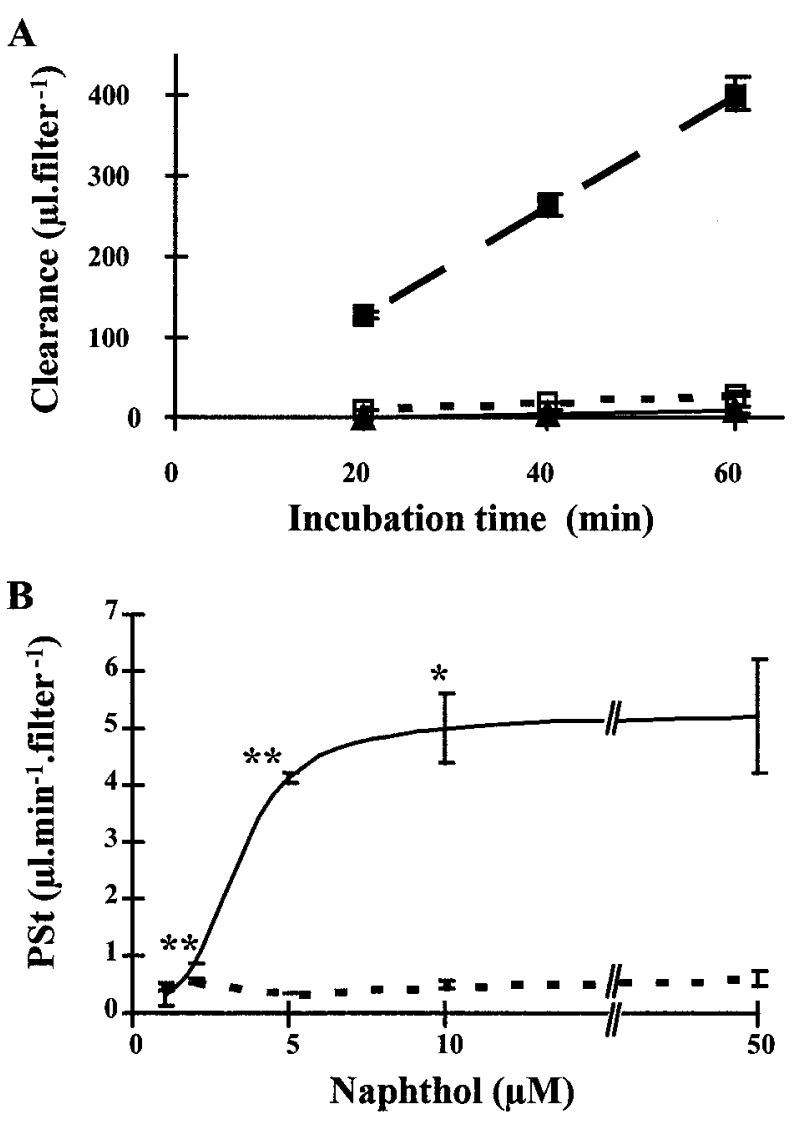

Figure 7. Metabolic barrier effect of choroidal epithelial cells on the transcellular passage of the lipophilic compound 1-naphthol. $A$, Clearance of 1-naphthol. One micromolar (triangle) or $50 \mu \mathrm{M}$ (filled square) 1-naphthol and $\left[{ }^{14} \mathrm{C}\right]$ sucrose (open square) as a tracer were added to the abluminal side of cells and renewed every 10 min to maintain the concentration close to a constant level in the donor compartment. The upper chamber was sampled every $20 \mathrm{~min}$. All results are expressed as mean \pm $\mathrm{SD}(n=3)$. All three clearance curves were linear. The large difference in the clearance of 1-naphthol between the two concentrations of the compound can be quantified by calculating the corresponding $\mathrm{PS}_{\mathrm{t}}$ values which are for this particular experiments of $0.17 \pm 0.07,6.85 \pm 0.36$, and $0.46 \pm 0.07 \mu \mathrm{l} / \mathrm{min}$ for $1 \mu \mathrm{M}, 50 \mu \mathrm{M}$ 1-naphthol, and $\left[{ }^{14} \mathrm{C}\right]$ sucrose, respectively. $B$, Effect of 1-naphthol concentration on its influx rate across the CPE cell monolayer. Cells were exposed on the abluminal membrane to decreasing concentrations of 1-naphthol (solid line) and to tracer concentration of $\left[{ }^{14} \mathrm{C}\right]$ sucrose (dotted line). $\mathrm{PS}_{\mathrm{t}}$ values, determined from the slopes calculated between 10 and $60 \mathrm{~min}$, decreased with decreasing concentration of 1-naphthol, and for $1 \mu \mathrm{M}$ reached sucrose value. All values are mean $\pm \mathrm{SD}$ ( $n=3$ to 5 from two experiments). Differences in 1-naphthol $\mathrm{PS}_{\mathrm{t}}$ values between a given concentration and the one below were determined by a one-tailed $t$ test for unequal variance, ${ }^{*} p<0.05$; ${ }^{* *} p<0.01$. For all concentrations, except for $1 \mu \mathrm{M}, \mathrm{PS}_{\mathrm{t}}$ values for 1-naphthol and sucrose were significantly different $(p<0.01)$ by a two-tailed $t$ test for unequal variance.

$(n=3)$, yielding a basolateral to apical ratio value of 3.2, fairly similar to that of NG. These data suggest that both glucuronides are exported via the same transporter, which thus, must exhibit some specificity toward the glucuronosyl moiety.

Because glucuronides are organic anions, we tested whether probenecid, a commonly used inhibitor of multispecific organic anion transport systems, had any effect on NG efflux from CPE cells. When $4 \mathrm{~V}$ monolayers were exposed to $50 \mu \mathrm{M}$ 1-naphthol in the presence of probenecid, NG export was reduced at both membranes to a similar extent and in a dose-dependent manner: $1 \mathrm{~mm}$ probenecid had a slight $12 \%$ decrease effect $(p<0.05)$,
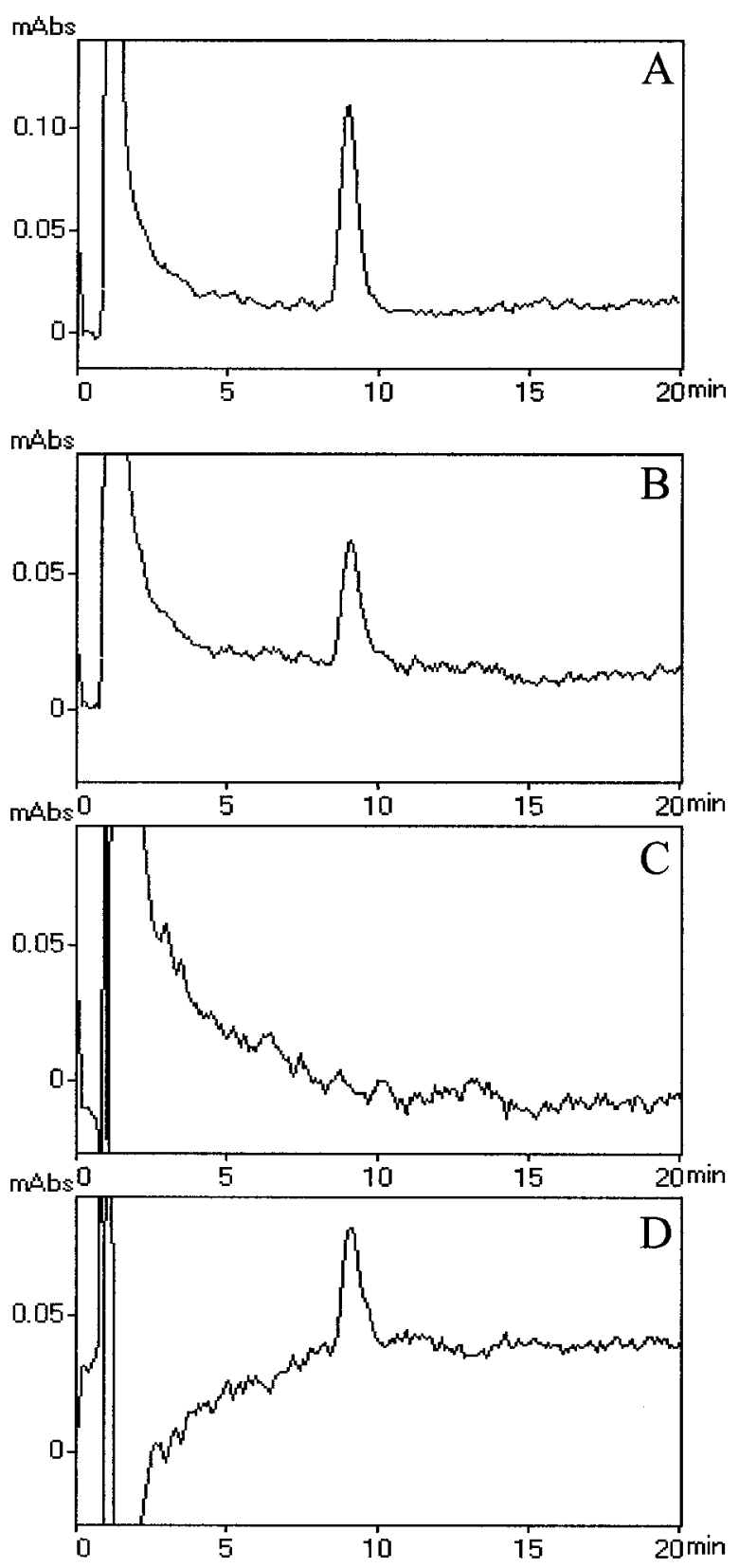

Figure 8. Reversed phase HPLC identification of 1-naphthyl- $\beta$ D-glucuronide as the metabolite released by cultured epithelial cells during exposure to 1-naphthol. $A$, HPLC profile obtained from a standard solution of 1-naphthyl- $\beta$-D-glucuronide. We injected 19 pmol of glucuronide. $B$, HPLC profile obtained from the cell incubation medium when $\beta$-glucuronidase is omitted from the reaction mixture, shows a peak coeluting with 1-naphthyl- $\beta$-D-glucuronide. $C$, Exposure to $\beta$-glucuronidase leads to a complete disappearance of the metabolite. $D$, Specific inhibition of $\beta$-glucuronidase by D-saccharic acid 1,4-lactone prevents the hydrolysis of 1-naphthyl- $\beta$-D-glucuronide present in the cell incubation medium. $C$ and $D$ profiles are corrected as described in Materials and Methods. When present $(B-D)$, 1-naphthol eluted at $40 \mathrm{~min}$.

whereas $4 \mathrm{~mm}$ probenecid caused a $65-75 \%$ inhibition $(p<0.01)$ (data not shown; Fig. 11). Higher doses of the inhibitor were not used because a slight increase in sucrose Pe was observed for 4 $\mathrm{mm}\left(0.47 \times 10^{-3} \pm 0.05 \times 10^{-3}\right.$ vs $0.33 \times 10^{-3} \pm 0.03 \times 10^{-3}$ $\mathrm{cm} / \mathrm{min} ; n=4)$, indicating that high doses of probenecid could 

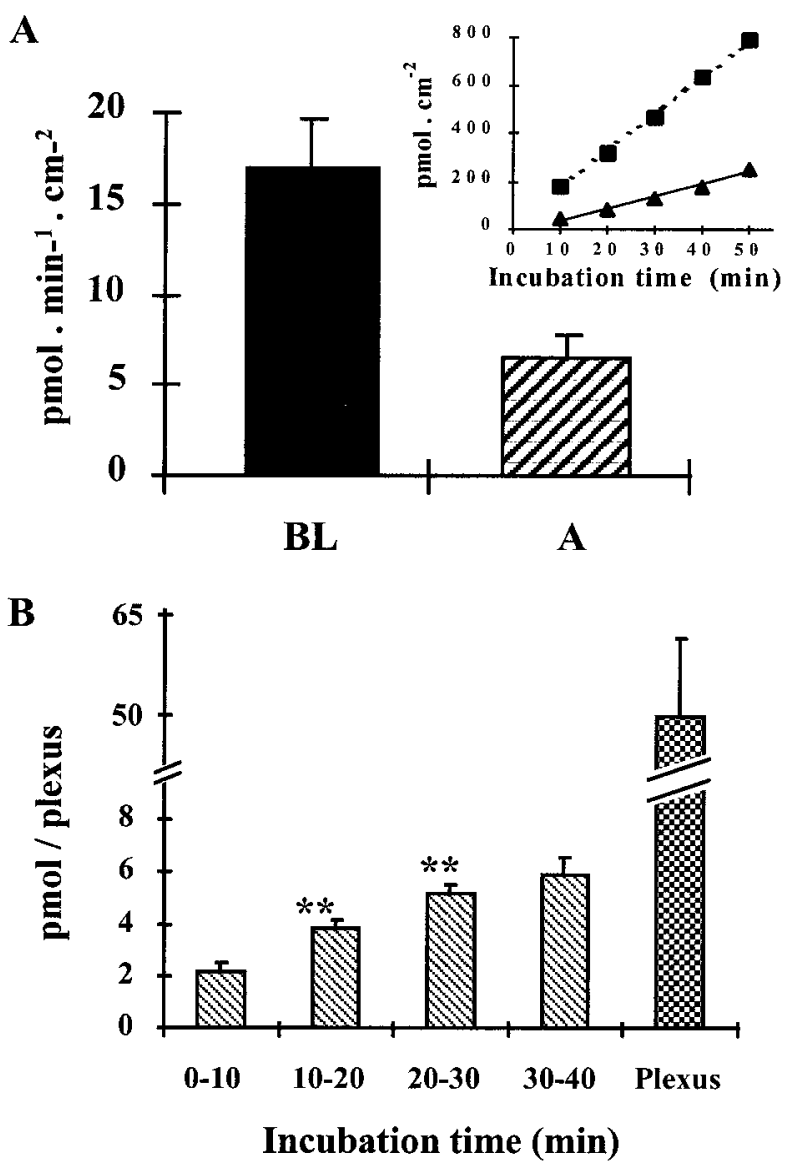

Figure 9. Polarized efflux of 1-naphthyl- $\beta$-D-glucuronide from 8-d-old $\mathrm{CPE}$ cell monolayers and from isolated choroid plexus. $A$, Cells from $4 \mathrm{~V}$ choroid plexuses were incubated with $50 \mu \mathrm{M}$ 1-naphthol in both compartments, which were renewed every $10 \mathrm{~min}$ (see Materials and Methods for details). Samples were taken from both the apical and the basolateral chambers every $10 \mathrm{~min}$ for $50 \mathrm{~min}$ and assayed for 1-naphthyl- $\beta$-Dglucuronide. Data from one experiment are shown as an example in the inset in which the cumulated amount of glucuronide excreted (in picomoles per square centimeter) is plotted versus time. Each time point is a mean value of two filters. The efflux process was linear over the $50 \mathrm{~min}$ period in the apical (triangle, solid line) and in the basolateral (square, dotted line) compartments. The export rates expressed in picomoles per minute per square centimeter (mean $\pm \mathrm{SD} ; n=10$ from four experiments) show a strong polarity of the efflux with $72 \%$ of the glucuronide released at the blood-facing membrane of the cells $(B L$, basolateral compartment; $A$, apical compartment). $B$, Isolated $4 \mathrm{~V}$ choroid plexuses were incubated with $50 \mu \mathrm{M}$ 1-naphthol. The incubation medium was changed every $10 \mathrm{~min}$ for $40 \mathrm{~min}$ and assayed for 1-naphthyl- $\beta$-Dglucuronide. At the end of the experiment, plexuses were digested, and their content in glucuronide was measured. Values expressed as picomoles effluxed (in case of incubates) or contained (in case of isolated tissue) per plexus are mean $\pm \mathrm{SD}(n=3)$. The increasing efflux during the three first sample periods and the large amount of NG retained in the tissue is another indication of a major basolateral, i.e., stroma-facing efflux from the choroidal epithelium, before its secondary release from the stroma into the incubation medium. Differences between one time point and the previous one were determined by a one-tailed $t$ test for unequal variance, ${ }^{* *} p<0.01$.

increase the paracellular pathway and exert toxic effects on the cell monolayer. For both concentrations, the reduced glucuronide efflux remained linear over time, indicating that probenecid effect occurred very rapidly (data not shown). The effect of probenecid was also reversible as shown in Figure 11. When cells exposed to the inhibitor for $20 \mathrm{~min}$ were washed and further incubated with

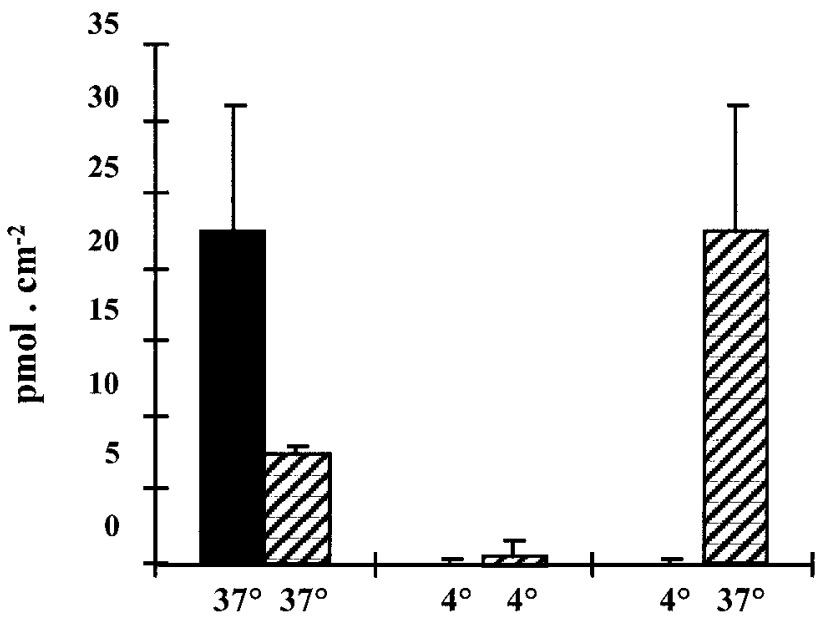

Figure 10. Effect of temperature on NG efflux from CPE cell monolayer. After a $20 \mathrm{~min}$ incubation at $37^{\circ} \mathrm{C}$ in $20 \mu \mathrm{M}$ 1-naphthol to allow for NG accumulation, LV CPE cells were rinsed at $4^{\circ} \mathrm{C}$. Efflux was then measured either for $2 \times 10 \mathrm{~min}$ at $37^{\circ} \mathrm{C}$, or $4^{\circ} \mathrm{C}$, or for $10 \mathrm{~min}$ at $4^{\circ} \mathrm{C}$ followed by 10 $\min$ at $37^{\circ} \mathrm{C}$. Values (in picomoles per square centimeter) represent the mean $\pm \mathrm{SD}(n=3)$ of the total amount of glucuronide excreted from the cell monolayer during the incubation period. The absence of glucuronide release when cells were kept at $4^{\circ} \mathrm{C}$ indicates that a transport process rather than passive diffusion is involved in the efflux of NG. When cells were rewarmed at $37^{\circ} \mathrm{C}$, the efflux resumed immediately. Filled columns, Efflux from 0 to $10 \mathrm{~min}$; hatched columns, efflux from 10 to $20 \mathrm{~min}$.

\section{Table 2. Passage of extracellular 1-naphthyl- $\beta$-D-glucuronide across} CPE cell monolayer

\begin{tabular}{lll} 
NG concentration & Apical to basolateral & Basolateral to apical \\
\hline $25 \mu \mathrm{M}$ & & \\
$\mathrm{NG}$ & $0.44 \pm 0.02$ & $0.41 \pm 0.02$ \\
Sucrose & $0.47 \pm 0.02$ & $0.44 \pm 0.02$ \\
$1 \mathrm{mM}$ & & \\
$\mathrm{NG}$ & $0.44 \pm 0.01$ & $0.42 \pm 0.03$ \\
Sucrose & $0.46 \pm 0.02$ & $0.45 \pm 0.03$
\end{tabular}

8 day-old LV CPE cell monolayers were exposed to either $25 \mu \mathrm{M}$ or $1 \mathrm{~mm}$ NG and to tracer concentration of $\left[{ }^{14} \mathrm{C}\right]$ sucrose on the apical or basolateral membrane. All results are expressed as $\mathrm{P}_{\mathrm{e}}\left(10^{-3} \mathrm{~cm} / \mathrm{min}\right.$, mean $\pm \mathrm{SD}, n=4$ filters $)$.

1-naphthol without probenecid, NG efflux resumed at a rate similar to that measured in untreated cells. Decrease in the export is not likely to be caused by UGT inhibition because (1) probenecid had no effect on UGT activity measured on choroid plexus homogenate (data not shown) and (2) the intracellular content in $\mathrm{NG}$ was increased from $18.9 \pm 2.7 \mathrm{pmol} /$ filter $(n=4)$ for DMSO to $30.8 \pm 4.7 \mathrm{pmol} /$ filter $(n=6)$ for $4 \mathrm{~mm}$ probenecid $(p<0.01$; one-tailed $t$ test for unequal variance).

Among probenecid-sensitive organic anion transport systems known to date, multidrug resistance-associated protein (MRP) has been implicated in the ATP-dependent cellular export of various glucuronidated compounds, a process that underwent competition from glutathione $S$-conjugates such as dinitrophenyl$S$-glutathione (Kobayashi et al., 1991; Jedlitschky et al., 1996; Loe et al., 1996). Because GS-DNP can be produced intracellularly by GSTs from extracellularly added CDNB (Evers et al., 1996), and GST activity toward CDNB is high in CPE cell homogenates (Fig. 6), we investigated whether this MRP substrate interacts with the export of NG. Loading of CPE cells with GS-DNP caused a marked reduction of $\mathrm{NG}$ efflux rate, as demonstrated by 


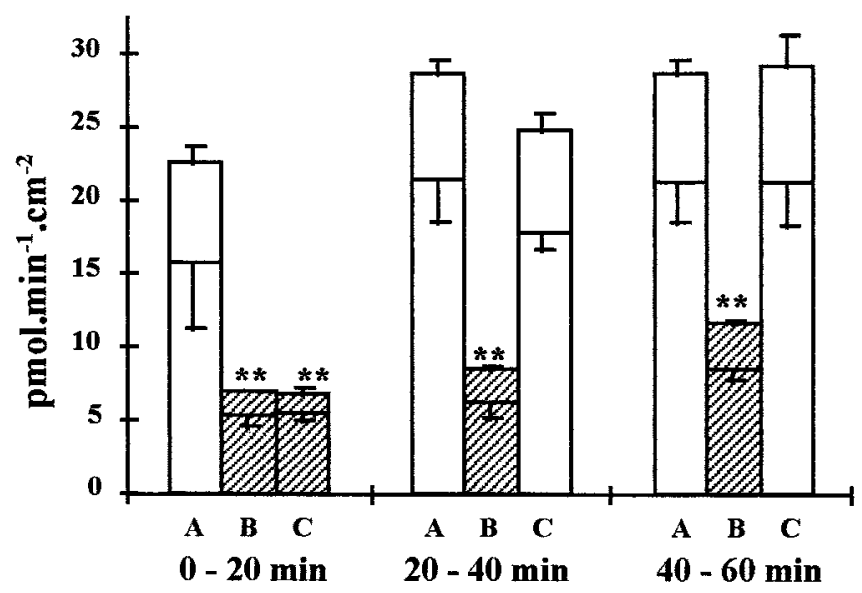

Figure 11. Reversible effect of probenecid on NG efflux from CPE cells. Cells were incubated at $37^{\circ} \mathrm{C}$ in $50 \mu \mathrm{M}$ 1-naphthol in the presence of $4 \mathrm{~mm}$ probenecid or DMSO (control experiments). After 20 min efflux, some probenecid-treated cells were washed and incubated in 1-naphthol without the inhibitor. Efflux was performed for another $2 \times 20 \mathrm{~min}$. NG was quantitated in both basolateral (bottom part of the bars), and apical (top part of the bars) compartment, at the end of each interval. Results expressed as picomoles per minute per square centimeter are the mean \pm SD $(n=4)$ of the amount of glucuronide excreted from the cell monolayer. For clarity, only half of SD bars are shown. A significant inhibition of total NG efflux occurred in the presence of probenecid $\left({ }^{* *} p<0.01\right.$; one-tailed $t$ test for unequal variance) and was fully reversible. Note that the residual efflux from probenecid-treated cells was polarized as in control cells. Open columns, Without probenecid; hatched columns, $4 \mathrm{~mm}$ probenecid. $A$, DMSO control; $B, 4 \mathrm{~mm}$ probenecid throughout; $C, 4 \mathrm{~mm}$ probenecid for $20 \mathrm{~min}$, DMSO for $2 \times 20 \mathrm{~min}$.

a decrease from $30.03 \pm 0.34 \mathrm{pmol} \cdot \mathrm{min}^{-1} \cdot \mathrm{cm}^{-2}$ in ethanoltreated cells $(n=4)$ to $3.26 \pm 1.05 \mathrm{pmol} \cdot \mathrm{min}^{-1} \cdot \mathrm{cm}^{-2}$ in CDNB-treated cells $(n=4)$. A moderate increase in the permeability to sucrose (2.3-fold) was concomitantly observed in monolayers treated with CDNB. However, intracellular NG content was not modified when cells were loaded with the glutathione conjugate, nor did CDNB inhibit UGT activity measured in a plexus homogenate. This indicates that the impaired efflux of NG is not caused by a decrease in NG production.

\section{DISCUSSION}

Insights into choroid plexus transport functions have been gained mainly by (1) in vitro uptake studies on dissected choroid plexus, (2) blood-to-choroid plexus uptake measurement or true CSF-toblood transepithelial flux measurement performed on isolated perfused sheep choroid plexus, (3) ventriculocisternal perfusion, (4) in situ brain perfusion coupled with cisterna magna CSF sampling or microdialysis (for review, see Davson and Segal, 1996). However, the results from the latter in vivo procedures may be impaired by CSF flow and complex pathway of circulation, and by CSF-brain exchanges (Ghersi-Egea et al., 1996). Establishment of in vitro cellular models of the choroid plexus epithelium to elucidate dynamic blood-CSF exchange mechanisms has been a challenge for the last few years. Several attempts have been performed from various species, using starting material from different developmental stages (Crook et al., 1981; Tsutsumi et al., 1989; Peraldi-Roux et al., 1990; Southwell et al., 1993; Ramanathan et al., 1996; Villalobos et al., 1997; Hakvoort et al., 1998; Zheng et al., 1998). Surprisingly, the data from these models have been mostly restricted to uptake and secretion. The few demonstrations of transepithelial flux of a molecule across choroidal cells were based on the measurement of an imbalance between its apical and basolateral concentrations, a method relevant only for active transport (Southwell et al., 1993; Hakvoort et al., 1998; Zheng et al., 1998). The cellular model and transfer technique we have developed allowed the characterization of transport-mediated and passive diffusion transfer in both directions, as well as cellular efflux mechanisms. We used newborn rat material to initiate our culture as (1) at this developmental stage, the choroidal epithelium already forms a tight and differentiated barrier, expressing transthyretin and drug-metabolizing enzymes (Tauc et al., 1984; Thomas et al., 1988; Strazielle and GhersiEgea, 1997b); (2) the size of choroid plexuses is already large and one litter provides sufficient material for 25 culture inserts; (3) the stromal core of the plexus is reduced in young animals compared with adults, which lessens the risk of fibroblast contamination. The cell isolation protocol we used gave highly reproducible monolayers of differentiated CPE cells, and, importantly, in contrast to other cellular models reported, fibroblast contamination was avoided without the use of growth inhibitors such as cytosine arabinoside or cis-hydroxyproline, which to some extent impede epithelial cell growth and functions. In addition, high levels of drug-metabolizing enzyme activities such as UGT, GST, or epoxide hydrolase were maintained in the cultured cells. This further confirms the differentiated status of the cultured CPE cells because these activities are valuable markers for differentiated cultured hepatocytes (Guillouzo, 1998).

Besides the structural and morphological features described in our reconstituted choroidal epithelium, a functional proof of its restrictive barrier property was provided by the fairly low monolayer permeability to sucrose, which reflects the paracellular pathway and appears sufficiently limited to allow precise measurement of permeability across the in vitro system. It should be noted that, although CPE cells are sealed in vivo by a continuous belt of tight junctions and strongly impede the passive diffusion of polar compounds, this epithelium is not as tight as the cerebral capillary endothelium forming the blood-brain barrier and has been classified, based on functional grounds, in the category of "leaky" epithelia (Castel et al., 1974; Davson and Segal, 1996).

This in vitro model of the blood-CSF barrier was used to investigate mechanisms of brain protection by the choroid plexus via an enzymatic barrier. Exposure of CPE cell monolayers to the lipophilic and cytotoxic compound 1-naphthol resulted in its conjugation into 1-naphthyl- $\beta$-D-glucuronide. Cellular export of this metabolite occurred predominantly at the basolateral, i.e., blood-facing membrane, thus facilitating its further elimination. This metabolic process will provide a complete barrier effect if the rate of metabolism $R_{m}$ is at least equal to the rate of naphthol penetration $R_{p}$ within the cells. The latter can be estimated according to Equation 3: $\mathrm{R}_{\mathrm{p}}=\mathrm{P}_{\mathrm{eH}} \times \mathrm{C}$, where $\mathrm{C}$ is the concentration of 1-naphthol in the incubation medium, and $\mathrm{P}_{\mathrm{eH}}$ is the permeability coefficient of 1-naphthol across the cell monolayer, measured for a high concentration of the compound, i.e., when the rate of metabolism is negligible with regard to the flux rate across the cells (such as $50 \mu \mathrm{M}$; see Fig. 7). Accordingly, we can assume $\mathrm{P}_{\mathrm{eH}}$ equal to the $\mathrm{P}_{\mathrm{e}}$ value of $12.5 \times 10^{-3} \mathrm{~cm} / \mathrm{min}$ obtained for $50 \mu \mathrm{M}$ 1-naphthol. The NG intracellular content after a $60 \mathrm{~min}$ incubation in $50 \mu \mathrm{M}$ naphthol was found negligible in comparison to the total amount of NG effluxed in the medium during the period (18 vs 1601 pmol, respectively, calculated from Fig. 10, group A). The maximal value for $\mathrm{R}_{\mathrm{m}}$ can therefore be approximated to the maximal rate measured for the metabolic/efflux process, i.e., $23.4 \mathrm{pmol} \cdot \mathrm{min}^{-1} \cdot \mathrm{cm}^{-2}$ (Fig. 9A). According to 
Equation 3 and assuming that the rate of metabolism is at its maximal velocity, then the enzymatic barrier will be fully efficient for concentrations up to $1.87 \mu \mathrm{M}$ (resulting from $\mathrm{R}_{\mathrm{m}} / \mathrm{P}_{\mathrm{eH}}$ ). This theoretical value is in agreement with the experimental concentration below which naphthol did not cross the monolayer. This correlation shows that the barrier effect is fully accounted for by metabolism. Moreover, our assumption about $\mathrm{R}_{\mathrm{m}}$ is justified because the apparent affinity constant of the metabolism-efflux process for 1-naphthol was estimated to be $<0.4 \mu \mathrm{M}$. Thus, this work demonstrates the presence in the choroid plexus, of a high-affinity conjugation/efflux process which, in conjunction with a highly efficient intracellular synthesis of the cosubstrate UDPglucuronic acid, functions as an effective metabolic barrier toward lipophilic compounds such as 1-naphthol.

Cellular efflux of NG is transporter-mediated as indicated by polarity, temperature sensitivity, unidirectionality, and inhibition of the process by other conjugates and by probenecid, which is known to block the transport of various organic anions in different epithelia. Organic anion transport systems have been investigated at the choroid plexus, mostly by in vitro uptake studies. In particular, clearance of CSF-borne naturally occurring organic anions such as leukotriene $\mathrm{C} 4$, taurocholate, or exogenous organic acids like salicylic acid and $\beta$-lactam antibiotics has been demonstrated to occur via the choroid plexus (Spector and Goetz, 1985; Susuki et al., 1997). Other recent works have reported the choroidal expression of organic anion transporter polypeptide oatp1 and oatp2 genes (Hogue-Angeletti et al., 1997; Abe et al., 1998). However, the involvement of these transporters in the efflux process of NG is unlikely because (1) oatp1 is located at the apical membrane of epithelial cells (Hogue-Angeletti et al., 1997), (2) oatp members are involved in cellular uptake processes rather than excretion (Oude Elferink et al., 1995), and (3) the range of substrates transported by oatp members does not apparently include glucuronide or glutathione conjugates except $17 \beta$ estradiol- $\beta$-D-glucuronide. The transport process we demonstrated is predominantly located at the basolateral membrane and outwardly directed. These data, and the recognition of the transporter by another glucuronoconjugate and by GS-DNP, strongly suggest the presence of a member of the MRP family at the basolateral membrane of the choroid plexus. These transporters first reported in tumor cells, (Marsh et al., 1986) have been described in normal tissues and circulating blood cells. They mediate the excretion of a large number of amphiphilic anions, most of which are conjugates of lipophilic compounds with glucuronide, sulfate, or glutathione (Leier et al., 1994; Jedlitschky et al., 1996; Loe et al., 1996). Six members of this family, exhibiting different tissue distribution and intracellular localization, have been identified to date (Cole et al., 1992; Büchler et al., 1996; Paulusma et al., 1996; Ito et al., 1997; Kool et al., 1997; Kiuchi et al., 1998; Uchiumi et al., 1998; Kool et al., 1999). Whereas MRP1 is found at the basolateral membrane of hepatocytes or transfected polarized pig kidney cells (Mayer et al., 1995; Evers et al., 1996), MRP2 has been demonstrated to localize to the apical domain of polarized epithelia such as the hepatocyte canalicular membrane or kidney proximal tubule luminal membrane (Schaub et al., 1997; Evers et al., 1998). The exact identity of the basolateral efflux pump in the choroidal epithelium remains to be determined.

In addition to UGT, other conjugating enzymes such as GSTs are likely to contribute to the enzymatic blood-CSF barrier phenotype, because GST activity and glutathione content are high in the choroid plexus (Fig. 6; Lowndes et al., 1994), and glutathione conjugates compete for the basolateral efflux transporter. This would be of particular importance for the CSF penetration and overall cerebral disposition of some anticancer drugs known to be MRP substrates either as glutathione conjugate or nonmodified (Cole and Deeley, 1998). Additionally, the MRP-like transport activity may be relevant to the basolateral efflux of neuroactive endogenous conjugates such as leucotriene C4 at the choroid plexus (Spector and Goetz, 1985).

In conclusion, the blood-CSF interface possesses a functional molecular machinery for all steps of endobiotic and xenobiotic metabolism and elimination. This paradigm of a coupled mechanism of metabolism-polarized efflux represents a new insight in understanding the contribution of choroid plexuses in the preservation of cerebral homeostasis. Furthermore, the role of the blood-CSF interface in the central bioavailability of neuroactive compounds can now be investigated with our in vitro choroidal epithelium model.

\section{REFERENCES}

Abe T, Kakyo M, Sakagami H, Tokui T, Tanemoto M, Nomura H, Hebert SC, Matsuno S, Kondo H, Yawo H (1998) Molecular characterization and tissue distribution of a new organic anion transporter subtype (oatp3) that transports thyroid hormones and taurocholate and comparison with oatp2. J Biol Chem 273:22395-22401.

Bondy C, Werner H, Roberts Jr CT, LeRoith D (1992) Cellular pattern of type-I insulin-like growth factor receptor gene expression during maturation of the rat brain: comparison with insulin-like growth factors I and II. Neuroscience 46:909-923.

Boulton M, Flessner M, Armstrong D, Hay J, Johnston M (1997) Lymphatic drainage of the CNS: effects of lymphatic diversion/ligation on CSF protein transport to plasma. Am J Physiol 1997 272:R1613-R1619.

Büchler M, König J, Brom M, Kartenberg J, Spring H, Horie T, Keppler D (1996) cDNA cloning of the hepatocyte canalicular isoform of the multidrug resistance protein, cMRP, reveals a novel conjugate export pump deficient in hyperbilirubinemic rats. $\mathrm{J}$ Biol Chem 217:15091-15098.

Castel M, Sahar A, Erlij D (1974) The movement of lanthanum across diffusion barriers in the choroid plexus of the cat. Brain Res 67:178-184.

Chodobski A, Loh YP, Corsetti S, Szmydynger-Chodobska J, Johanson CE, Lim YP, Monfils PR (1997) The presence of arginine vasopressin and its mRNA in rat choroid plexus epithelium. Mol Brain Res 48:67-72.

Chomczynsky P, Sacchi W (1987) Single-step method of RNA isolation by acid guanidium thiocyanate-phenol-chloroform extraction. Anal Biochem 162:156-159.

Cole SP, Bhardwaj G, Gerlach JH, Mackie JE, Grant CE, Almquist KC, Stewart AJ, Kurz EU, Duncan AM, Deeley RG (1992) Overexpression of a transporter gene in a multidrug-resistant human lung cancer cell line. Science 258:1650-1654.

Cole SPC, Deeley RG (1998) Multidrug resistance mediated by the ATP-binding cassette transporter protein MRP. BioEssays 20:931-940.

Crook RB, Kasagami H, Prusiner SB (1981) Culture and characterization of epithelial cells from bovine choroid plexus. J Neurochem 37:845-854.

Dansette P, Dubois GC, Jerina DM (1970) Continuous fluorimetric assay of epoxide hydrolase activity. Anal Biochem 97:340-345.

Davson H, Segal MB (1996) Physiology of the CSF and blood-brain barriers. Boca Raton: CRC.

Dehouck M-P, Meresse S, Delorme P, Fruchart J-C, Cecchelli R (1990) An easier reproducible and mass-production method to study the blood-brain barrier in vitro. J Neurochem 54:1798-1801.

Dickson PW, Howlett GJ, Schreiber G (1985) Rat transthyretin (prealbumin): molecular cloning, nucleotide sequence, and gene expression in liver and brain. J Biol Chem 260:8214-8219.

Evers R, Zaman GJR, van Deemter L, Janssen H, Calafrat J, Oomen LCJM, Oude Elferink RPJ, Borst P, Schinkel AH (1996) Basolateral localization and export activity of the human multidrug resistanceassociated protein in polarized pig kidney cells. J Clin Invest 97:1211-1218.

Evers R, Kool M, van Deemter L, Janssen H, Calafrat J, Oomen LCJM, 
Paulusma CC, Oude Elferink RPJ, Baas F, Schinkel AH, Borst P (1998) Drug export activity of the human canalicular multispecific organic anion transporter in polarized kidney MDCK cells expressing cMOAT (MRP2) cDNA. J Clin Invest 101:1310-1319.

Fanning AS, Jameson BJ, Jesaitis LA, Anderson JA (1998) The tight junction protein $\mathrm{ZO}-1$ establishes a link between the transmembrane protein occludin and the actin cytoskeleton. J Biol Chem 273:29745-29753.

Ghersi-Egea J-F, Walther B, Decolin D, Minn A, Siest G (1987) The activity of 1-naphthol-UDP-glucuronosyltransferase in the brain. Neuropharmacology 26:367-372.

Ghersi-Egea J-F, Minn A, Daval J-L, Jayyosi Z, Arnould V, Souhaili-ElAmri H, Siest G (1989) NADPH: cytochrome P-450 (c) reductase: biochemical characterization in rat brain and cultured neurons and evolution of activity during development. Neurochem Res 14:883-888.

Ghersi-Egea J-F, Leininger-Muller B, Suleman G, Siest G and Minn A (1994) Localization of drug-metabolizing enzyme activities to bloodbrain interfaces and circumventricular organs. $J$ Neurochem 62:1089-1096.

Ghersi-Egea J-F, Finnegan W, Chen J, Fenstermacher JD (1996) Rapid distribution of intraventricularly administered sucrose into cerebrospinal fluid cisterns via subarachnoid velae in rat. Neuroscience 75:1271-1288.

Guillouzo A (1998) Liver cell models in in vitro toxicology. Environ Health Perspect 106[Suppl]:511-532.

Habig WH, Pabst MJ, Jakoby W (1974) Glutathione $S$-transferases. The first enzymatic step in mercapturic acid formation. J Biol Chem 249:7130-7139.

Hakvoort A, Haselbach M, Galla HJ (1998) Active transport properties of porcine choroid plexus cells in culture. Brain Res 795:247-256.

Hogue Angeletti R, Novikoff PM, Juvvadi SR, Fritschy JM, Meier PJ, Wolkoff AW (1997) The choroid plexus epithelium is the site of the organic anion transport protein in the brain. Proc Natl Acad Sci USA 94:283-286.

Ishikawa T (1992) The ATP-dependent glutathione $S$-conjugate export pump. Trends Biochem Sci 17:463-468.

Ito K, Suzuki H, Hirohashi T, Kume K, Shimizu T, Sugiyama Y (1997) Molecular cloning of canalicular multispecific organic anion transporter defective in EHBR. Am J Physiol 272:G16-G22.

Jedlitschky G, Leier I, Buchholz U, Barnouin K, Kurz G, Keppler D (1996) Transport of glutathione, glucuronate and sulfate conjugates by the MRP gene-encoded conjugate export pump. Cancer Res 56:988-994.

Johanson CE (1995) Ventricles and cerebrospinal fluid. In: Neuroscience in medicine (Conn M, ed), pp 171-196. Philadelphia: JB Lippincott.

Johnson JA, El Barbary A, Kornguth SE, Brugge J-F, Siegel FL (1993) Glutathione $S$-transferase isoenzymes in rat brain neurons and glia. J Neurosci 13:2013-2023.

Kato M, Soprano DR, Makover A, Kato K, Herbert J, Goodman DS (1986) Localization of immunoreactive transthyretin (prealbumin) and of transthyretin mRNA in fetal and adult rat brain. Differentiation 31:228-235.

Kiuchi Y, Suzuki H, Hirohashi T, Tyson CA, Sugiyama Y (1998) cDNA cloning and inducible expression of human multidrug resistance associated protein 3 (MRP3). FEBS Lett 433:149-52.

Kobayashi K, Komatsu S, Nishi T, Hara H, Hayashi K (1991) ATPdependent transport for glucuronides in canalicular plasma membranes vesicles. Biochem Biophys Res Commun 176:622-626.

Kool M, de Haas M, Scheffer GL, Scheper RJ, van Eijk MJ, Juijn JA, Baas F, Borst P (1997) Analysis of expression of cMOAT (MRP2), MRP3, MRP4, and MRP5, homologues of the multidrug resistance-associated protein gene (MRP1), in human cancer cell lines. Cancer Res 57:3537-3547.

Kool M, van der Linden M, de Haas M, Baas F, Borst P (1999) Expression of human MRP6, a homologue of the multidrug resistance protein gene MRP1, in tissues and cancer cells. Cancer Res 59:175-182.

Lam BK, Xu K, Atkins MB, Austen KF (1992) Leukotriene C4 uses a probenecid-sensitive export carrier that does not recognize leukotriene B4. Proc Natl Acad Sci USA 89:11598-11602.

Leier I, Jedlitschky G, Buchholz U, Cole SP, Deeley RG, Keppler D (1994) The MRP gene encodes an ATP-dependent export pump for leukotriene $\mathrm{C} 4$ and structurally related conjugates. J Biol Chem 269:27807-27810.

Leininger-Muller B, Ghersi-Egea J-F, Siest G, Minn A (1994) Induction and immunological characterization of the uridine diphosphateglucuronosyltransferase conjugating 1-naphthol in the rat choroid plexus. Neurosci Lett 175:37-40.

Lindvall M, Hardebo JE, Owmann C (1980) Barrier mechanisms for neurotransmitter monoamines in the choroid plexus. Acta Physiol Scand 108:215-221.

Loe DW, Almquist KC, Cole SPC, Deeley RG (1996) ATP-dependent $17 \beta$-estradiol 17-( $\beta$-D-glucuronide) transport multidrug resistance protein (MRP). Inhibition by cholestatic steroids. J Biol Chem 271:9683-9689.

Lowndes HE, Beiswanger CM, Philbert MA, Reuhl KR (1994) Substrates for neural metabolism of xenobiotics in adult and developing brain. Neurotoxicology 15:61-73.

Marsh W, Sicheri R, Center MS (1986) Isolation and characterization of adriamycin-resistant HL-60 cells which are not defective in the initial intracellular accumulation of drug. Cancer Res 47:4053-4057.

Mayer R, Kartenbeck J, Buchler M, Jedlitschky G, Leier I, Keppler D (1995) Expression of the MRP gene-encoded conjugate export pump in liver and its selective absence from the canalicular membrane in transport-deficient mutant hepatocytes. J Cell Biol 131:137-150.

Miettinen M, Clark R, Virtanen I (1986) Intermediate filament proteins in choroid plexus and ependyma and their tumors. J Androl 123:231-240.

Misfeldt DS, Hamamoto ST, Pitelka DR (1976) Transepithelial transport in cell culture (renal epithelium). Proc Natl Acad Sci USA 73:1212-1216.

Nilsson C, Lindvall-Axelsson M, Owman C (1992) Neuroendocrine regulatory mechanisms in the choroid plexus-cerebrospinal fluid system. Brain Res Rev 17:109-138.

Oude Elferink RPJ, Meijer DKF, Kuipers F, Jansen PLM, Groen AK, Groothuis GMM (1995) Hepatobiliary secretion of organic compounds; molecular mechanisms of membrane transport. Biochim Biophys Acta 1241:215-268.

Paulusma CC, Bosma PJ, Zaman GJ, Bakker CT, Otter M, Scheffer GL, Scheper RJ, Borst P, Oude Elferink RP (1996) Congenital jaundice in rats with a mutation in a multidrug resistance-associated protein gene. Science 271:1126-1128.

Peraldi-Roux S, Nguyen-Than Dao B, Hirn M, Gabrion J (1990) Choroidal ependymocytes in culture: expression of markers of polarity and function. Int J Dev Neurosci 8:575-588.

Peters A, Palay S, Webster H deF (1991) The fine structure of the nervous system. Neurons and their supporting cells, Ed 3. New York: Oxford UP.

Petersen G (1977) A simplification of the protein assay method of Lowry et al. which is more generally applicable. Anal Biochem 83:346-356.

Ramanathan VK, Hui AC, Brett CM, Giacomini KM (1996) Primary cell culture of the rabbit choroid plexus: an experimental system to investigate membrane transport. Pharm Res 13:952-955.

Saito Y, Wright EM (1983) Bicarbonate transport across the frog choroid plexus and its control by cyclic nucleotides. J Physiol 336:635-648.

Schaub TP, Kartenbeck J, Konig J, Vogel O, Witzgall R, Kriz W, Keppler D (1997) Expression of the conjugate export pump encoded by the mrp2 gene in the apical membrane of kidney proximal tubules. J Am Soc Nephrol 8:1213-1221.

Segal MB, Preston JE, Collis CS, Zlokovic BV (1990) Kinetics and Na-independence of amino acid uptake by blood side of perfused sheep choroid plexus. Am J Physiol 258:F1288-F1294.

Siflinger-Birnboim A, Del Vecchio PJ, Cooper JA, Blumenstock FA, Shepard JM, Malik AB (1987) Molecular sieving characteristics of the cultured endothelial monolayer. J Cell Physiol 132:111-117.

Southwell BR, Duan W, Alcorn D, Brack C, Richardson SJ, Kohrle J, Schreiber G (1993) Thyroxine transport to the brain: role of protein synthesis by the choroid plexus. Endocrinology 133:2116-2126.

Spector R (1985) Thymidine transport and metabolism in choroid plexus: effect of diazepam and thiopental. J Pharmacol Exp Ther 235:16-19.

Spector R (1986) Nucleoside and vitamine homeostasis in the central nervous system. Ann NY Acad Sci 481:221-230.

Spector R, Goetz EJ (1985) Leukotriene C4 transport by the choroid plexus in vitro. Science 228:325-327.

Strazielle N, Ghersi-Egea J-F (1997a) Cerebral drug penetration and metabolism at the blood-cerebrospinal fluid barrier: an in vitro approach. J Physiol (Lond) 505:51P.

Strazielle N, Ghersi-Egea J-F (1997b) Drug metabolism in newborn rat 
choroid plexus from lateral, third and fourth ventricle. Dev Anim Vet Sci 27:895-901.

Strazielle N, Ghersi-Egea J-F (1998) Drug conjugation and polarized excretion of conjugates at the rat blood-cerebrospinal fluid barrier. Soc Neurosci Abstr 24:1564.

Strazielle N, Ghersi-Egea J-F (1999) Implication of blood-brain interfaces in cerebral drug metabolism and drug metabolite disposition. In: Molecular drug metabolism and toxicology, Chap 12 (Williams G, Aruoma OI, eds). London: OICA International, in press.

Strobel HW, Dignam J (1978) Purification and properties of NADPHcytochrome P-450 reductase. In: Methods in enzymology (Fleisher SE, Packer I, eds), pp 89-93. London: Academic.

Suzuki H, Terasaki T, Sugiyama Y (1997) Role of efflux transport across the blood-brain and blood-cerebrospinal fluid barrier on the disposition of xenobiotics in the central nervous system. Adv Drug Delivery Rev 25:257-285.

Tauc M, Vignon X, Bouchaud C (1984) Evidence for the effectiveness of the blood-CSF barrier in the fetal rat choroid plexus. A freeze-fracture and peroxidase diffusion study. Tissue Cell 16:65-74.

Thomas SA, Segal MB (1996) Identification of a saturable uptake system for deoxyribonucleosides at the blood-brain and blood-cerebrospinal fluid barriers. Brain Res 741:230-239.

Thomas T, Power B, Hudson P, Schreiber G, Dziadek M (1988) The expression of transthyretin mRNA in the developing rat brain. Dev Biol $125: 415-427$.
Tsutsumi M, Skinnert MK, Sanders-Bush E (1989) Transferrin gene expression and synthesis by cultured choroid plexus epithelial cells. J Biol Chem 264:9626-9631.

Tu GF, Aldred AR, Southwell BR, Schreiber G (1992) Strong conservation of the expression of cystatin $\mathrm{C}$ gene in choroid plexus. Am J Physiol 263:R195-R200.

Uchiumi T, Hinoshita E, Haga S, Nakamura T, Tanaka T, Toh S, Furukawa M, Kawabe T, Wada M, Kagotani K, Okumura K, Kohno K, Akiyama S, Kuwano M (1998) Isolation of a novel human canalicular multispecific organic anion transporter, cMOAT2/MRP3, and its expression in cisplatin-resistant cancer cells with decreased ATPdependent drug transport. Biochem Biophys Res Commun 252:103-110.

Villalobos AR, Parmelee JT, Pritchard JB (1997) Functional characterization of choroid plexus epithelial cells in primary culture. J Pharmacol Exp Ther 282:1109-1116.

Wilson AS, Davis CD, Williams DP, Buckpitt AR, Pirmohamed M, Park BK (1996) Characterization of the toxic metabolite(s) of naphthalene. Toxicology 114:233-242.

Yamamoto M, McCaffery P, Drager UC (1996) Influence of the choroid plexus on cerebellar development: analysis of retinoic acid synthesis. Dev Brain Res 93:182-190.

Zheng W, Zhao Q, Graziano JH (1998) Primary culture of choroidal epithelial cells: characterization of an in vitro model of blood-CSF barrier. In Vitro Cell Dev Biol 34:40-45. 